\title{
Why a World State is Inevitable
}

\author{
ALEXANDER WENDT \\ University of Chicago
}

Long dismissed as unscientific, teleological explanation has been undergoing something of a revival as a result of the emergence of selforganization theory, which combines micro-level dynamics with macrolevel boundary conditions to explain the tendency of systems to develop toward stable end-states. On that methodological basis this article argues that a global monopoly on the legitimate use of organized violence - a world state - is inevitable. At the micro-level world state formation is driven by the struggle of individuals and groups for recognition of their subjectivity. At the macro-level this struggle is channeled toward a world state by the logic of anarchy, which generates a tendency for military technology and war to become increasingly destructive. The process moves through five stages, each responding to the instabilities of the one before - a system of states, a society of states, world society, collective security, and the world state. Human agency matters all along the way, but is increasingly constrained and enabled by the requirements of universal recognition.

KeY Words $\bullet$ cultures of anarchy $\bullet$ downward causation $\bullet$ logic of anarchy self-organization struggle for recognition $\downarrow$ teleology - world state

In this article I propose a teleological theory of the 'logic of anarchy' which suggests that a world state is inevitable (cf. Buzan et al., 1993). Like any structural tendency, the speed with which this one will be realized is historically contingent. At the micro-level the process is neither deterministic nor linear, and forward movement may be blocked for periods of time. There are many pathways by which a world state may be achieved, and human agency matters along every one. In that sense 'anarchy is [still] what states make of it' (Wendt, 1992). However, I am not concerned here with historical contingencies or timing. My own guess is that a world state will

European Journal of International Relations Copyright (C) 2003

SAGE Publications and ECPR-European Consortium for Political Research, Vol. 9(4): 491-542

[1354-0661 (200312) 9:4; 491-542; 038724] 
emerge within 100-200(?) years, but nothing below turns on that prediction. Instead, I am concerned with the macro-structure of all pathways, which channel the international system's development toward an inevitable end-state. In that respect the theory is progressivist, although in an explanatory rather than normative sense.

Resistance to progressivist, much less teleological, thinking runs deep within contemporary IR scholarship. Realists are skeptical, arguing that the logic of anarchy is one of endless conflict and war (Waltz, 1979). Liberals are more optimistic, arguing that international institutions, interdependence and/or democratic states can lead to cooperation and peace within anarchy (Keohane, 1990). However, liberal progressivism is contingent, not teleological. If institutions are upheld, if interdependence deepens and/or if democracy spreads, then progress is possible. The forecast is based on extrapolating lawlike regularities from the past into the future, assuming certain conditions continue to hold. Since there is no guarantee they will, we cannot say that any given future is inevitable.

Indeed, if there is one thing almost all social scientists today agree on, from the most hardened positivists to the most radical postmodernists, it is that teleological explanations are illegitimate. To call a theory 'teleological' is considered a decisive criticism, with no need even to explain why. This may be due to the fact that teleology has been considered unscientific since the triumph of the mechanistic worldview in the 17th century, and is also sometimes thought to deny human agency in the social world. In my view both objections are unfounded, and with them a priori resistance to teleological thinking about world politics.

To show this, in the first section I synthesize recent attempts to rehabilitate teleological explanation. These efforts span many disciplines and indicate that, although the scientific status of teleology remains controversial, it is being taken increasingly seriously. One reason is that much of this literature builds on self-organization theory, which is emerging as an important challenge to the neo-Darwinian theory of evolution. ${ }^{1}$ Selforganization theory hypothesizes that order in nature emerges not only through the mechanism of mutation-selection-retention, but also 'spontaneously' from the channeling of system dynamics by structural boundary conditions toward particular end-states. With a few exceptions this theory has been little noticed by IR scholars, ${ }^{2}$ who are just beginning to engage neo-Darwinism. ${ }^{3}$ But in the social sciences more generally the idea of selforganization has been around since the 'spontaneous order' tradition of the Scottish empiricists, and is getting considerable attention today. ${ }^{4}$ Much of this work is not teleological, and many self-organization theorists might vigorously reject any such reading of their approach. On the other hand, 
many others do see a connection, arguing that self-organization theory provides a scientific basis for teleological explanation. ${ }^{5}$

Assuming that is possible, toward what end-state does the international system move, and by what mechanism does it get there? Three end-states suggest themselves - a pacific federation of republican states, a realist world of nation-states in which war remains legitimate, and a world state. The first is associated with Kant (199la, 1991b) and the second with Hegel (1977), both of whom based their projections on explicitly teleological arguments. ${ }^{6}$ In rejecting the possibility of a world state, therefore, they agreed that, strictly speaking, anarchy would remain the organizing principle of the system, albeit different kinds of anarchy. As to the mechanism of progress, in different ways Kant and Hegel also both emphasized the role of conflict Kant in man's 'unsociable sociability', and Hegel in the 'struggle for recognition'.

I am in no position here to engage in an exegesis and critique of Kant and Hegel's arguments. However, since I share their emphasis on conflict as a mechanism of development but reach a different conclusion, it may be useful to introduce my argument by highlighting two ways in which it departs from theirs. The first concerns the effects of conflict on state identity. While envisioning a tendency for conflict to create republican states, Kant did not expect them to develop a collective identity. His states remain egoists who retain their sovereignty. Hegel provides the basis for a different conclusion, since the effect of the struggle for recognition is precisely to transform egoistic identity into collective identity, and eventually a state. But Hegel expects this outcome only in the struggle between individuals. States too seek recognition, but in his view they remain self-sufficient totalities. Their struggle for recognition does not produce supranational solidarity, leaving us at the 'end of history' with a world of multiple states (also see Fukuyama, 1992). Some critics have suggested that Hegel's reasoning here is inconsistent, and that he should have argued for a world state. ${ }^{7}$ Be that as it may, I argue that the struggle for recognition between states will have the same outcome as that between individuals, collective identity formation and eventually a state (cf. Walzer, 1986). One reason for this concerns the second difference in my approach, which concerns the role of technology. Kant rejected the possibility of a world state in part because the technology of his day precluded it (Carson, 1988: 177; Guyer, 2000: 416-17), and in positing an end-state in which war remained legitimate Hegel did not think its costs would become intolerable. Neither anticipated the dramatic technological changes of the past century, which are in part caused by the security dilemma and thus endogenous to anarchy. As Daniel Deudney $(1999,2000)$ convincingly argues, these changes have greatly increased the costs of war and also the scale on which it is possible to organize a state. 
With these material changes the struggle for recognition among states undermines their self-sufficiency and makes a world state inevitable. Via the struggle for recognition, in short, the logic of anarchy leads to its own demise.

Two caveats. First, it is impossible within the constraints of an article to do justice to both the methodological and substantive issues in this discussion. That might have counseled two separate articles (at least), but given the modern hostility to teleology the argument might be dismissed a priori without a defense of its methodology, and the latter might seem unmotivated without a 'plausibility probe'. So at the risk of doing both inadequately I have joined them. However, on the assumption that the logic of teleological explanation will be less familiar and of broader interest than a theory of world state formation, when faced with trade-offs I have opted for preserving discussion of the former, and left the substantive theory more at the level of a sketch, to be fleshed out in the future. Second, again for reasons of space, I shall not address the relationship between the logic of anarchy and the 'logic of capital', which forms a distinct developmental dynamic in the system. The logic of capital generates distributional struggles that cannot be reduced to the struggle for recognition (Fraser, 2000) and, as such, would significantly complicate the latter, but in the long run it too points toward a world state (Chase-Dunn, 1990; Shaw, 2000). So I bracket its role here, on the assumption that it only makes a world state 'more' inevitable.

The teleological explanation is defended in the next section. I then explain what I shall mean by the state, including a world state. In the third section I discuss the struggle for recognition, and the fourth show why such a struggle within anarchy should culminate in a world state. The role of agency in this process is addressed in the conclusion.

\section{Causal Pluralism and Teleological Explanation}

In recent years there has been much debate within IR scholarship about what might be called 'causal pluralism' (Asma, 1996) - whether explanations of world politics can take different forms. The orthodox positivist position, rooted in a Newtonian worldview, is that an explanation always depicts a mechanical relationship between prior conditions and later effects. ${ }^{8}$ Other forms of inquiry might be valuable as 'descriptive inference' (King et al., 1994), but they do not explain. Explanations must be causal, and causation must be mechanical. From this perspective, causal pluralism is either confused about what 'explanation' means, or a threat to science itself. Following interpretivist philosophers of social science, constructivists and postmodernists have argued against causal monism in favor of 'constitutive' 
analyses. Some see their work as yielding 'Understanding' and thus outside the 'Explaining' paradigm altogether (Hollis and Smith, 1990), whereas others see it as a form of explanation (Ruggie, 1998: 871-4; Wendt, 1998). But all agree that constitutive theories are not merely descriptive, and contribute to social science in ways that cannot be reduced to mechanical causation.

The ultimate question here is whether different kinds of causes exist in nature. ${ }^{9}$ If causal monism is based on the Newtonian worldview, then the prototype for causal pluralism is the Aristotelian worldview that it replaced. Advocates of constitutive theory in IR have not offered an Aristotelian-style defense of their approach. ${ }^{10}$ Doing so might be instructive, and suggests that teleological explanation should be added to the pluralist agenda.

Aristotelians distinguish four kinds of causality. (1) 'Efficient' causality refers to a mechanical relationship between a prior cause and a subsequent effect. This is how positivism defines causation. (2) 'Material' causality refers to the sense in which an entity or process is caused by having a particular composition. (3) 'Formal' causality refers to the way in which the structure of an object or process gives it form. (4) 'Final' causality - the key element in teleology - refers to the way in which the purpose or end of a system affects its development. A textbook example of these multiple causes at work is building a house (Ulanowicz, 1997: 12) - its efficient cause is the labor of workmen; its material cause is the bricks and mortar of which it is made; its formal cause is the blueprint that gives these materials their eventual form; and its final cause is the purposes of the individuals building it. Significantly, all four causes are seen as necessary to complete explanations, and will be at least implicit in any scientific theory. So the goal is not pluralism for pluralism's sake, but to obtain a total understanding of a phenomenon.

If the positivist view of explanation presupposes efficient causation, then constitutive analyses offer intriguing parallels to material and formal causation. In IR such arguments have usually been used to emphasize the importance of ideas, although material conditions can be constitutive as well. Thus, constitutive theorists have shown how phenomena normally seen as material, such as power, are in fact constituted by ideas ('material' causation). And these ideas exist and have effects because of the discursive forms (norms, institutions, ideologies) in which they are embedded (formal causation). This is not the place to defend the explanatory content of such accounts. The point is only that the a priori rejection of their explanatory status assumes causal monism. However, positivists and post-positivists alike reject final causation. If causal pluralism justifies constitutive theory, then perhaps it can do the same for teleology. 


\section{Teleological Explanation ${ }^{11}$}

Teleological explanations explain by reference to an end or purpose toward which a system is directed. Like other explanations they are answers to a question (Cross, 1991; Wendt, 1998), in this case 'what is X for?' As such, they often take the grammatical form of 'for the sake of' or 'in order to' statements $-\mathrm{Y}$ is the final cause of $\mathrm{X}$ if $\mathrm{X}$ happens in order to realize $\mathrm{Y} .{ }^{12}$ Ever since Francis Bacon, philosophers have tried to discredit such explanations as unscientific, and show that they can always be reduced to mechanical causation. Yet interest in teleology has recently come back. One reason is a widespread sense that efficient causation cannot account for apparent end-directedness in nature, so that some 'explanatory structure' is lost if teleological reasoning is excluded altogether. ${ }^{13}$

The contemporary literature on teleological explanation is deeply divided about how it should be defined. The differences concern two main questions - (1) whether non-intentional or only intentional processes may be teleological (McLaughlin, 2001; cf. Mayr, 1982); and (2) whether teleological explanation is essentially backward- or forward-looking. In my view these choices are complementary rather than opposed, and we should let substantive considerations determine them rather than stipulate 'correct' ones in the abstract. Thus, my argument about world state formation has both intentional and non-intentional elements, and although it is forwardlooking this does not preclude a role for backward-looking accounts.

In an intentional teleological process the end toward which a system moves is a goal of a purposive agent, whose desire for an outcome helps bring it about. Final causation here involves goal-seeking, which is found at least in the higher animals, and perhaps all organisms. However, the paradigm case is human action, where explanations by reference to reasons (or desires and beliefs), as in rational choice theory, may be seen as teleological. Few social scientists think of rational choice theory as teleological, on the assumption that 'reasons are [efficient] causes' (see Davidson, 1963). But that is contested. ${ }^{14}$ Many philosophers treat reasons as constitutive and thus formal causes, while others go further, treating them as final causes. ${ }^{15}$

In contrast, in a non-intentional teleological process the end toward which a system moves is constituted by non-conscious boundary conditions. The paradigm case is ontogeny, the process by which embryos become adults. Here there is no goal-seeking (a puppy does not seek to become a $\operatorname{dog}$ ), and therefore no 'purpose'. But the process is still end-directed, since unless interrupted by disease or death a normal organism will inevitably become an adult. Mechanists argue that this too can be reduced to efficient causation, making appeals to final causation spurious. Teleologists disagree, 
arguing that the end-state toward which organisms develop is an essential part of the explanation of how they get there.

Assuming that both intentional and non-intentional processes can be teleological, which one best describes the logic of world state formation? That depends in part on whether it makes sense to attribute intentionality to any social system, and the world system in particular. While philosophically debatable, the assumption that at least some social systems - namely states - are intentional pervades IR scholarship. ${ }^{16}$ I shall make the same assumption, and so at the 'micro'-level my argument is intentional. However, it is less clear that intentionality characterizes the world system as a whole. Since my burden here is already great, at the macro-level I will play it safe and make my argument on non-intentional grounds, speculating only at the end about how the system's history might be retold in intentional terms.

Within the non-intentional category, in turn, there is a debate about whether teleological explanation should be understood in backward- or forward-looking terms. The two approaches have many similarities, but differ on the central question of what such explanations explain. ${ }^{17}$

The backward-looking approach assumes that when someone asks a 'what-for?' question she wants to know how and why a system acquired certain traits or behaviors (Wright, 1976). The question is about origins, and is answered by giving an etiology or history of the trait in terms of its consequences for survival. A teleological explanation of zebra stripes, for example, would show how they were functional for the differential retention of zebras in natural selection, just as one of the Westphalian system might show how a monopoly of force gave states a competitive advantage against groups without one (cf. Spruyt, 1994). Like neo-Darwinism, therefore, this conception of teleology is concerned with populations of organisms, and so it might be called an 'evolutionary' approach to teleology. This convergence may seem counter-intuitive, since neo-Darwinism is strongly antiteleological. However, evolutionary teleologists argue that neo-Darwinism contains an implicit teleological element that does irreducible explanatory work. ${ }^{18}$ This element is hidden in the definition of what will enhance fitness in a given context, which constitutes the functional principle in terms of which consequences are selected (Machamer, 1977; Short, 1983: 314). In the savannah camouflage is a criterion of fitness, the consequences of which explain zebra stripes, just as in anarchy an advantage in war may explain states.

The forward-looking approach to teleological explanation answers a different question. On this view, 'what-for?' questions are asking how some trait or behavior serves the functions of a larger system. The question here is about how things work, not where they came from. In biology this leads to 
a concern with the maturation of individual organisms, not populations of them, and so it might be called a 'developmental' approach to teleology. This is more akin to Aristotle's view of teleology, and indeed, in the developmentalist view the evolutionists have totally changed the subject, reducing teleology to a special kind of efficient causation. ${ }^{19}$ That may make it palatable to modern science, but also strips it of much of its interest. However that may be, since the international system is a single system, my approach to world state formation is developmental. This offers an interpretation of teleology clearly different than efficient causal explanation, and as such is a strong form of the argument.

As yet there is no authoritative non-intentional, developmental account of teleological explanation. However, the literature consistently points to the interaction of two processes, a micro or bottom-up process of selforganization, and a macro or top-down process of structural constitution. The former involves efficient causation and the latter formal causation, neither of which is intrinsically teleological. ${ }^{20}$ Final causation emerges from their interaction.

\section{Self-Organization and Upward Causation}

The micro-foundations of teleological processes are described by selforganization theory, which shows how order can emerge in a system as a result of the interactions of elements following purely local rules. Adam Smith's 'invisible hand' is perhaps the most well-known example of such a dynamic (Ullman-Margalit, 1978). A more recent example is Thomas Schelling's (1971) classic study of racial segregation. Schelling built a simple model of an initially completely white neighborhood which showed that, if families vary in their tolerance for black neighbors, with a few leaving the neighborhood when the first black family moves in, more when two black families move in, and so on, the eventual result will be a wholly black neighborhood, even though almost no white families were opposed ex ante to living in an integrated one. Similarly, in his application of complexity theory to world politics, Robert Jervis (1997) reads balance of power theory in self-organizational terms - as a result of decisions taken by individual states in response to local threats, a macro-level pattern of balancing emerges over time. In each case, systemic order grows from a bottom-up or 'upward causal' process, without central coordination. In this respect selforganization theory has a strong methodological individualist orientation (Epstein and Axtell, 1996: 16-17).

The mechanisms by which order grows are negative and positive feedback (see Jervis, 1997). Negative feedback can work either at the micro-level by punishing individuals' behavior, or at the macro-level through systemic 
compensation (as in stock market corrections). Both help to maintain a system's status quo, or 'homeostasis', as in the operation of the balance of power in anarchy. Negative feedback has been amply studied by social scientists in the past without self-organization theory (Witt, 1997: 490-1), and so the theory's novelty lies primarily in its emphasis on positive feedback, in which behaviors or effects are amplified by a dynamic of 'increasing returns' (Pierson, 2000) or 'autocatalysis' (Swenson, 1997). ${ }^{21}$ Importantly, when positive feedback effects cross a threshold or 'tipping point' the resulting non-linear dynamics can induce system change.

There is nothing intrinsically teleological about negative and positive feedback. Both involve only efficient causation, albeit of a circular or reciprocal kind, in which $\mathrm{X}$ causes $\mathrm{Y}, \mathrm{Y}$ feeds back on $\mathrm{X}, \mathrm{X}$ stabilizes or reinforces $\mathrm{Y}$, and so on. Self-organization theorists who focus on such feedback dynamics tend not to see their work as teleological. On other hand, some self-organization theorists do make a connection to teleological explanation, suggesting the latter's status in the theory is currently unresolved (Hodgson, 2001: 369). The feature of self-organizing systems that raises the question is their end-directedness, which is generated by the interaction of self-organization with macro-level boundary conditions exercising downward causation on a system's parts.

\section{Boundary Conditions and Downward Causation}

Just as self-organization theory's bottom-up story is rooted in methodological individualism, the top-down story is rooted in methodological holism. Holism describes systems that have a structural integrity constituting them as irreducible totalities, or more than the sum of their parts (Wendt, 1999). This integrity stems from macro-level organizing principles or boundary conditions, which separate a system from its environment and impose a degree of 'closure' on its internal processes. ${ }^{22}$ Boundary conditions may be organic (like DNA) or social (like cultures of anarchy, see below). What both types share is that they encode information at the system level. This does not mean that the system exists wholly separate from its elements, just that it is not reducible to them. Parts and whole are mutually constitutive - parts only have the identity they do in virtue of the whole (one cannot be a slave if there is no slavery), and the whole cannot exist without its parts. Holism implies a hierarchy of interdependent levels, each having its own causal powers. ${ }^{23}$

The conventional view of the relationship between levels involves only upward causation - the interaction of elements at the micro-level generates patterns at the macro. Such reductionism assumes that all causation is mechanistic. Armed with the concept of formal causation, however, we can 
make sense of the holist claim that systems have a top-down explanatory role. A familiar example in world politics is the way in which the norms of the Westphalian system constitute states with external sovereignty, an irreducibly social status with rights and obligations that would not exist without those norms. This example describes a static effect of the system. A more dynamic formal causal effect is captured by the concept of 'downward causation'.

Downward causation refers to the way in which boundary conditions constrain and govern the interaction of a system's parts. ${ }^{24}$ The effect here is conservative, geared to system maintenance (see Juarrero, 1999: 131-50). The information within boundary conditions defines what kinds of interactions are inconsistent with the operation of a system, and on this basis the system selects for the behavior and character of its parts, which 'determine[s] in part the distribution of lower level events and substances' ${ }^{25}$ The 'in part' here is important, since there may be many ways to satisfy a system's requirements - they may be 'multiply realizable' - the choice of which occurs at the micro-level. ${ }^{26}$ To that extent the effect of macro-level constraints will be weak (Juarrero, 1999: 126). However, this does not undermine the main point that by virtue of their boundary conditions, systems are able to monitor and intervene in their own functioning to sustain themselves. ${ }^{27}$ This presupposes an efficient causal mechanism and as such depends on interactions at the micro-level (cf. Elster, 1982), but it is not reducible to the latter, since efficient causation requires the separate existence of cause and effect. In a structured totality parts and whole are mutually constitutive, which means their interaction cannot be mechanical (Emmeche et al., 2000: 25; Juarrero, 1999: 133).

Downward causation may be conceptualized in terms of a 'program'. ${ }^{28}$ The conventional view of explanation is process-oriented - we explain $\mathrm{X}$ by identifying the micro-level process that caused it. Often this approach is sufficient, but in situations where an outcome is multiply realizable it will fail to capture relevant explanatory facts and so lack 'causal depth' (Meyering, 2000: 190; R. Wilson, 1994). Although he does not use this terminology, a good example in IR scholarship is Waltz's (1979) theory of how anarchy causes balancing. A process theory of balancing would look to the microlevel at how individual states perceive and react to threats. Such a theory would tend to see balancing as intentional. In contrast, Waltz looks to the macro-level at how the anarchic structure of the international system 'selects' for balancing - over time states that fail to balance are simply eliminated, leaving only balancers. ${ }^{29}$ Importantly, his theory does not require that states intend to balance or even be aware of the system's logic. In effect, the anarchy 'program' controls what kinds of efficient causal 
pathways get activated, enabling Waltz to introduce a higher-level explanatory framework that simplifies the data relative to process-explanations, and from which we can derive testable hypotheses. ${ }^{30}$

\section{End-Directedness and Final Causation}

Teleological explanation depends on the interaction of bottom-up and topdown causation, but requires one more element. Downward causation is biased toward homeostasis and so does not explain change, and selforganization theory's upward causal focus on non-linear dynamics does not explain their direction. What is missing is an explanation of the tendency of systems to progress toward a state of 'completed development' (Jacobs, 1986: 51). For this we need to add final causation to the picture, which refers to the role of end-states in channeling system dynamics toward certain outcomes. It is the interaction of all three forms of causation (along with material causation, which is implicit in this discussion) that constitutes teleological processes. ${ }^{31}$

Self-organization theory refers to end-states as 'attractors', which come in four types - fixed-point (corresponding to equilibria in economics), periodic, quasi-periodic and chaotic. ${ }^{32}$ Each represents a distinct pattern toward which a system may move and lock into, after which it settles down into a self-sustaining logic. We might say that the system is then organized as opposed to organizing, even though an ongoing process is necessary for its continued survival. Which attractor characterizes a given system depends on its boundary conditions. Waltz's claim that anarchy tends toward balancing (and thus continued anarchy) implies a fixed-point attractor, as does my claim that it tends toward a world state.

A common way to think about the explanatory role of end-states is that events at the micro-level are selected by a system in relation to its future states. ${ }^{33} \mathrm{~A}$ specification of these states is essential to a complete theory of a system's development over time, without which we would lose some explanatory power. Imagine trying to explain the development of an organism without a conception of what it will look like as an adult - clearly something would be missing from such an account. With end-states added to the picture, we get an understanding of how a system governs not just the reproduction but also the becoming of its parts.

Since much of the modern hostility to teleology stems from misunderstandings of the role of end-states, let me briefly address two. First, it does not mean the future causes the present, or 'backward causation'. It is not the end-state itself that generates an outcome, but the boundary 
conditions that constitute the end-state which do. Thus, the real issue here is the legitimacy of holism and downward causation (McLaughlin, 2001: 27), not the future having causal powers. Second, skeptics have often complained that since all organisms inevitably die, teleology implies the absurd claim that death is the purpose of life. This too is mistaken. Death is not an end-state, since a dead system is no longer a 'system'. End-states are defined by the stage at which systems have reached an attractor, not by what happens afterward. That all organisms die proves only that they eventually lose their battle to sustain themselves. ${ }^{34}$

What precisely is it that causes systems to develop toward their end-states? The general answer is instability (Buss, 1987). As we saw above, the boundary conditions of self-organizing systems select among their elements for behaviors and properties that are consistent with system maintenance, but this process is not deterministic, since there are usually many ways to maintain a system. This means that a lot may happen at the micro-level that is not controlled by the macro. These happenings will periodically generate dynamics that threaten a system's viability. A developing system will respond to such threats by elaborating its structure - encoding new information in its boundary conditions - so as to further constrain its elements. Insofar as that stabilizes the system temporarily it will constitute a 'local' attractor. However, with each elaboration of structure new sources of instability may emerge at the micro-level, to which the system will respond with further elaboration, which may create yet more instabilities, and so on until a 'global' attractor or end-state is reached, at which point the system's dynamics become self-enforcing. In a sense, then, the logic here is 'running to stand still', with movement in a progressive direction until a system need run no more.

The fact that development toward end-states involves a suppression of destabilizing interactions at the micro-level is one reason why critics worry about the implications of systemic teleologies for human agency (cf. Peled, 2000). I will return to this issue in the conclusion, but a few remarks are called for here. It is true that because development by its nature is a movement from indeterminacy to determinacy (Salthe and Matsuno, 1995: 329), there is a reduction in the scope for individual agency. In a world state, for example, member states lose the freedom to make war unilaterally. Yet, in two key respects agency is preserved in teleological explanations. First, multiple realizability means that considerable room for agency may exist in choosing the path by which the system develops. Second, the loss of some agency at the micro-level may create agency at the macro-level. ${ }^{35}$ By taking war off the agenda, a world state would create capacities for collective action that its members could never realize in an anarchy. 


\section{Falsifying Teleological Explanations}

Little attention has been given in the literature to how one evaluates teleological explanations, but as a general rule we would want to know two things. First, what are the deep structures or boundary conditions that are thought to generate end-directedness in a system? These structures may be unobservable and so accessible only indirectly, but in this respect teleological claims are no harder to falsify than any structural explanation. ${ }^{36}$ Second, does a system's development consistently result in a certain end-state? In biology this question is easy to answer, since we can observe the life course of organisms. But in IR that is not possible, since the world system has not yet reached its end-state. That poses a hard epistemological problem - how can we know whether a world state is inevitable before the system gets there?

There is no easy answer to this question, but at least three kinds of empirical evidence nevertheless seem relevant. The first is the history of the international system to date. Do we observe a tendency for political authority to consolidate into larger units? Of interest here is Robert Carneiro's (1978) estimate that in $1000 \mathrm{BC}$ there were 600,000 independent political communities on the earth, whereas today there are about 200. Notwithstanding the difficulties of counting 'states' 3000 years ago, and their increase in the 20th century due to decolonization, the trend is striking and prima facie evidence for some kind of developmental process. ${ }^{37}$ The second is histories of existing states, which can be seen as local attractors in regional sub-systems. These sub-systems may be more open than the world system and thus more vulnerable to exogenous shocks, but if my theory of world state formation is right their development should be explicable at least in part by the same logic. Finally, one might simulate the argument with a computational model and see if it generates the predicted result. Cederman's $(1997,2001)$ work is instructive in this regard. Although not explicitly teleological or addressed to the struggle for recognition, it points to distinct developmental tendencies in anarchy. None of this evidence will be decisive given the difficulties of knowing the world system's end-state from 'inside history', but by making at least some evaluation possible it does suggest that what follows is a scientific conjecture.

In sum, teleological explanation involves four distinct kinds of causation - material, efficient/upward, formal/downward and final. I turn now to the world system. Since I have elsewhere argued for the centrality of ideas in constituting world politics (Wendt, 1999), I shall bracket the material causation story which follows. In the next two sections I focus on the micro side of the argument, after which I turn to the macro side. 


\section{Defining the State}

The first step is to specify the parts of the system. Ultimately these are individuals, but from the beginning of history individuals have organized themselves into autonomous political communities, and it is through that medium that they have mostly interacted within the world system as a whole. As such, there are two levels of parts in the system, individuals and groups. In this section I define the main political groups in today's system (states), which will also yield a definition of the world state. I return to individuals in the next section.

Historically, politically autonomous groups have taken many forms tribes, city-states, empires, leagues, and so on - but over time this variety has been reduced to a single form today, the territorial state. If the theory is correct this convergence was itself inevitable, but I shall not argue that here (cf. Spruyt, 1994), since it is not essential to my argument that states be the only autonomous groups in the system. It is enough that states are dominant, which allows us to focus on them as the relevant groups. ${ }^{38}$

Following Weber (1978), I define the state as an organization possessing a monopoly on the legitimate use of organized violence within a society (Wendt, 1999). This definition has four aspects that matter, below.

The first is a monopoly of force. This means that the potential for organized violence is unified in the sense that those controlling its exercise cannot make decisions independent of each other, but always operate as a 'team'. ${ }^{39}$ With Hobbes (1968), let's call this 'common power'.

The second aspect is legitimacy. Those subject to a common power must perceive its existence and operation as right. Legitimacy is constituted by a structure of political authority that empowers some people to enforce the rules and obligates others to obey (Benjamin and Duvall, 1985: 25-6). As such, it is conferred not by the state itself but by members of society, who 'surrender private judgment' over the enforcement of social order to the state (Blau, 1963: 307). That precludes from being states groups that maintain a monopoly of force solely through violence and coercion, like armed gangs, but within that constraint the basis of state legitimacy can vary. Monarchies, communist states, even charismatic dictatorships - in certain historical circumstances all could be seen as legitimate by their subjects. Importantly, this means that a 'Weberian state' need not satisfy the more stringent requirement of a 'Hegelian state', namely equal recognition of all its members (see later). Given my concern with the struggle for recognition, therefore, I shall in effect be arguing that we will get a Weberian world state by creating a Hegelian one.

Common power and legitimacy together constitute the third aspect, sovereignty, defined as the exclusive right to enforce the law of the land. This 
right is first and foremost an internal right conferred by society. Internal sovereignty might also be recognized by other states in a society of states (external sovereignty), but this is not essential to stateness. In Carl Schmitt's (1985) view, sovereignty comes down to the ability to decide unilaterally that certain individuals or groups are not part of the community and so may if necessary be killed. The unaccountability of such decisions will emerge below as a key driver in world state formation.

Finally, the state is a corporate actor. This actor is made up of many individuals and as such is also a structure, but the particular characteristics of that structure constitute a collective intentionality, an ability of its members to act consistently as a single agent. ${ }^{40}$ What makes corporate agency possible? Self-interest and coercion clearly play a role. If individuals do not perceive a state as in their interest it may not last long, and if they take up arms against the state it will coerce them. But a stable structure of collective intentionality requires more, a shared belief among its members that they constitute a collective identity or 'We', to which they are willing to subordinate their private judgment. The result is a 'group mind', in which individuals define their identities and interests in terms of membership in a group (D. Wilson, 1997; R. Wilson, 1994), enabling them to engage in institutionalized collective action. In short, the state's agency is irreducible to its members, which means that states are capable of goal-seeking behavior.

On this definition a world state is clearly some way off, and would require three fundamental changes to the current world system. ${ }^{41}$ The first is the emergence of a universal security community - members of the system must no longer routinely perceive each other as physical threats, and expect to settle their disputes peacefully (Adler and Barnett, 1998). This does not mean that an enforcement mechanism would be superfluous, since there is always the possibility of 'crime', but a generalized security dilemma would not exist. The second is universal collective security - if crime does occur, other members of the system must act as if a threat to one is a threat to all. Together these two changes would create a global common power. The third is universal supranational authority - a procedure for making binding and legitimate decisions about the exercise of this common power. This would require territorial states to surrender sovereignty to a global subjectivity in the security domain, and as such goes beyond collective security and Kant's pacific federation, in which states retain their sovereignty. As in territorial states today, cooperation with a world state would be mandatory and enforceable. Since I have defined the territorial state partly in terms of sovereignty, this would in effect mean that the elements of a world state would no longer be 'states' in a strict sense, but local realizations of a larger state. 
Given the magnitude of such changes, a Weberian criterion constitutes a 'hard case' for any claim that a world state is inevitable. ${ }^{42} \mathrm{~A}$ non-Weberian approach, especially if it relaxes the monopoly of force requirement, could suggest that a world state is already here (the UN?) or just around the corner (Shaw, 2000), which would make the argument easier but less interesting. Yet, in light of the internationalization of political authority that has already occurred in the system without a centralization of force - in the form of the $\mathrm{UN}, \mathrm{EU}, \mathrm{WTO}$, ICC, and so on - there is the question of whether a Weberian approach unnecessarily constrains our imagination about what the system's end-state might be. Perhaps it won't be a 'state' at all, but a 'pacific federation', 'polity' (Ougaard and Higgott, 2002), 'neo-medieval' system (Friedrichs, 2001), or some other as yet unimagined form in which there is no monopoly of force. Perhaps, but in my view these would be only transitional structures, and that the political development of the system will not end until the subjectivity of all individuals and groups is recognized and protected by a global Weberian state. The key problem for any other architecture is unauthorized violence by rogue Great Powers. Until Great Power violence is accountable the system will be prone to instability, and so will continue its development until the Weberian criteria are met.

Lest I be accused of lacking imagination, however, it should be emphasized that the systemic changes needed for a world state could be fulfilled in various ways, and so a world state might look very different than states today. In particular, it could be much more decentralized, in three respects. First, it would not require its elements to give up local autonomy. Collectivizing organized violence does not mean that culture, economy or local politics must be collectivized; subsidiarity could be the operative principle. Second, it would not require a single UN army. As long as a structure exists that can command and enforce a collective response to threats, a world state could be compatible with the existence of national armies, to which enforcement operations might be sub-contracted (along the lines of NATO perhaps). Finally, it would not even require a world 'government', if by this we mean a unitary body with one leader whose decisions are final (cf. Bull's [1977] 'domestic analogy'). As long as binding choices can be made, decision-making in a world state could involve broad deliberation in a 'strong' public sphere rather than command by one person (Mitzen, 2001). In short, as long as it has a common power, legitimacy, sovereignty and agency we should not prejudge the form a world state might take. The EU is already not far from meeting these requirements on a regional level. Were a 'completed' EU to be globalized it would be a world state.

By way of integrating the discussion it may be useful to summarize this view of the state in teleological terms. States are created and sustained in an 
upward causal fashion by the self-organizing interaction of their members. This interaction is structured by boundary conditions - internally in the form of enforceable rules, externally in the form of territorial closure which through downward causation constitute states as distinct systems. And as self-organized systems states have reached an at least local end-state in their development.

\section{The Struggle for Recognition}

Historically states have always existed in the plural, and so the emergence of a world state requires the transformation of their identities to a global basis. This task is complicated by the fact that territorial states are local attractors. To be sure, they are always in process, maintained by practices of 'domestic' and 'foreign policy' that constitute them as distinct units (Campbell, 1992; Jackson and Nexon, 1999), but these practices sustain homeostatic logics that are resistant to change. ${ }^{43}$ Nevertheless, I argue that territorial states are not stable in the long run. They may be local equilibria, but they inhabit a system that is in disequilibrium, the resolution of which leads to a world state. The mechanism that generates this outcome is the interaction between struggles for recognition at the micro-level and cultures of anarchy at the macro. In this section I address the former, and in the next the latter.

The struggle for recognition is about the constitution of individual and group identities and thus ultimately about ideas, but it is mediated by material competition. Since the material aspect of the story has already been partly told by Deudney, and might be thought sufficient to generate a world state, I begin there as a way of showing the necessity of the identity aspect. I do so, however, under the assumption that they form an integrated whole.

\section{Material Competition}

The material aspect of the struggle for recognition relates to the Hobbesian justification for territorial states. ${ }^{44}$ However, in the hands of Hobbes and most realists it points to continued anarchy not a world state. ${ }^{45}$ Only with Herz (1957) do we find a clear realist argument for the eventual transcendence of the state, which Deudney $(1999,2000)$ has systematized in his thesis of 'nuclear one-worldism'. ${ }^{46}$ Neither Herz nor Deudney make the teleological claim that a world state is inevitable, and by themselves their arguments cannot sustain such a view. But they do provide an essential piece of the story.

Hobbes (1968) justified the state on the grounds that only through obedience to a common power could individuals escape a 'nasty, brutish, and short' life in the state of nature. A common power is necessary because 
of the physical equality and vulnerability of human beings - since even the weak can kill the strong, it is in everyone's interest to accept the security provided by a state. The argument is in effect a rationalist one. Death being the ultimate cost, the expected utility of obeying the state is greater than that of enduring the state of nature. Yet, Hobbes argued that this reasoning did not apply between states. States are not as vulnerable to being 'killed' as individuals, and so the state of nature they face is more tolerable. This asymmetry undercuts realist descriptions of world politics as 'Hobbesian' (Heller, 1982; cf. Mearsheimer, 2001), but also seems to justify realist skepticism that anarchy would lead to a world state.

Deudney challenges this conclusion by arguing that the scale on which it is functional for states to provide security is related to the destructiveness of coercive technology. As evolution in the 'forces of destruction' raises the 'violence interaction capacity' in the system, it becomes more costly for relative equals to fight, making it more efficient to organize their security on a common basis (Deudney, 2000). The repeated efforts to create collective security systems after major wars in 1815,1918 and 1945 attest to this incentive. Similarly, when the development of military technology is asymmetric it becomes easier for stronger states to expand their territories at the expense of weaker ones, as we saw in the late medieval expansion of European states and in colonialism as a result of gunpowder and artillery. The scale of surviving states may have been efficient for many centuries, but ballistic missiles and nuclear weapons are now making them obsolete as well. Missiles can easily penetrate territorial frontiers, and combined with nuclear weapons enable an aggressor to 'kill' a state in one quick blow. Compared to the 'billiard ball' pre-nuclear state, states in a nuclear world are more like 'eggs', whose shells are easily shattered by determined attack (Deudney, 1995: 228). In these material conditions states are no longer able to provide security for their members, and become as vulnerable as individuals in the state of nature. Hence nuclear one-worldism - just as the risks of the state of nature made it functional for individuals to submit to a common power, changes in the forces of destruction increasingly make it functional for states to do so as well. ${ }^{47}$

Despite its apparently end-directed character, Deudney's theory locates the primary cause of integration outside the states system, in exogenous changes in technology (1999: 108). These changes are contingent and transmitted to the system in efficient causal fashion, and so he rightly cautions that although it is becoming functional for security to be organized on a global scale, this does not mean it will necessarily happen. In short, he does not attribute a telos to the system, and as such defends only the 'probability' of integration, not its inevitability (1999: 102).

However, the security dilemma suggests that technological development 
is (also) endogenous to the system, giving its material aspect a teleological logic. States may not trust each other's intentions, and since in anarchy there is no third party upon which to count for security, they are forced to rely on their own resources to deal with threats. The result is the familiar arms race spiral - even if it has no aggressive intentions, a fearful state is forced to arm, forcing its neighbors to arm in response, threatening the first state more, and so on. Importantly, this logic creates an incentive for qualitative competition, since a technological lead may confer victory in war. Not all states will act on that incentive, but those that do will gain an advantage, which other states are then forced to imitate or die, thereby ratcheting up the minimum technology necessary for security. In this way anarchy generates a tendency for technology and war to become more destructive over time, and with it upward pressure on the optimal scale of states.

It might be thought that this material dynamic is enough by itself to make a world state inevitable, but that is not the case, for two reasons. First, as Gregory Kavka (1987: 304) points out, the condition of states in a nuclear world differs in a critical respect from that of individuals in a state of nature - Mutual Assured Destruction means that a nuclear aggressor cannot expect to survive a war. Thus, even though states are vulnerable to being 'killed' by nuclear attack, if they are not suicidal we can expect them to be deterred by credible threats of retaliation. By holding the costs of intolerable war at bay, MAD ensures that the vulnerability of states in anarchy is not as desperate as that of individuals, which means they may prefer a nuclear stand-off to giving up sovereignty to a world state, as we saw in the Cold War.

A second problem is linked by Kavka to an under-appreciated feature of Hobbes' story. Hobbes used his theory to justify obedience to an existing state (by warning people what would happen if they did not obey), not to justify creating a new one out of the state of nature. It was a retrospective theory. This matters because even if we accept Hobbes' rationale for obeying an existing state, when used prospectively - which is how it must figure in a theory of world state formation - his theory is vulnerable to a collective action problem. The fact that it is collectively rational to submit to a common power does not mean that it is individually rational. In anarchy people might not trust each other enough to form a state, even if that results in a sub-optimal world. For such insecure actors, it is only after a state is created that it becomes rational to sign the social contract, since only then can they trust it to be enforced. Moreover, even if people submit to a common power, what guarantees the security of its members (soldiers and police) from each other? They face a state of nature all over again - each is armed and a potential threat to others, and there is no still higher common power to protect them. Appealing to the authority of the sovereign won't 
work, since for Hobbes this depends ultimately on a monopoly of force, the possibility of which is precisely what is at issue here. Used prospectively, in other words, Hobbes' reasoning leads to an infinite regress and so cannot make a world state inevitable, even though it might be functional after the fact.

What is missing from the materialist theory of world state formation is an account of identity change. It assumes that actors in the pre-state situation are the same as actors in the post-state - rational, self-interested maximizers. What changes with the creation of a state are only the costs and benefits of compliance, not the identities and interests of its inhabitants. The same assumption underlies Kant's rejection of the world state. Even though republican states trust each other enough to achieve perpetual peace, their identity as egoists facing a logic of contract does not change. ${ }^{48}$ Thus, to argue that a world state is inevitable we need an explanation for why the boundaries of state identity will expand to include all people, not just their original members.

\section{The Struggle for Recognition}

Hegel's discussion of the struggle for recognition is the subject of an extensive literature in contemporary political theory, which exhibits a wide range of opinion not just on its normative status but even what precisely it is about. Moreover, most of this scholarship is concerned with struggles for recognition within states, which is a different context than the international system, where violence is a legitimate option. Since I cannot review the scholarly debate here, much less offer a reading of Hegel, what follows is a perhaps idiosyncratic understanding of the struggle ${ }^{49}$ reflecting in part the context of anarchy. I address three issues in turn - the desire for recognition and its relationship to collective identity or solidarity; the instability of asymmetric recognition; and two levels on which the struggle for recognition is played out in world politics.

Recognition and Solidarity. Like Neorealism my argument is structural. However, to generate any movement in a structural theory we have to assume that actors want something, so that at the micro-level there must be a goal-seeking (and thus teleological) element. Neorealists assume that above all else people want physical security (Waltz, 1979: 126), which means that what the logic of anarchy is 'about' is a struggle for security. I agree that people want security. However, I think they also want recognition, which means that the logic of anarchy is also about a struggle for recognition. Since Neorealists expect continued anarchy rather than a world state these two struggles may point in different directions. But there is also an intriguing 
possibility that the struggle for recognition may actually explain much of the realpolitik behavior, including war, which Neorealists have attributed to the struggle for security (Fukuyama, 1992: 255). This merits further research (see Ringmar, 2002 for a good start).

A precondition for recognition is a simple fact of difference or alterity. Individuals are given as different by virtue of their physical bodies, and states are given as different by virtue of the boundaries they draw between themselves and other states. ${ }^{50}$ These facts may or may not be recognized by other actors. Recognition is a social act that invests difference with a particular meaning - another actor ('the Other') is constituted as a subject with a legitimate social standing in relation to the Self. This standing implies an acceptance by the Self of normative constraints on how the Other may be treated, and an obligation to give reasons if they must be violated. The Other begins to 'count' (Williams, 1997: 199). Actors that are not recognized, like a slave or an enemy in the state of nature, do not count and so may be killed or violated as one sees fit.

The latter possibility is one reason why actors might desire recognition, as the Israeli-Palestinian conflict suggests. However, there is more to the desire for recognition than simply physical security, for it is through recognition by the Other that one is constituted as a Self in the first place. We can see this dependence of Self on Other in our everyday identities - one cannot be a teacher without recognition by students, a husband without recognition by a wife, a citizen without recognition by other citizens. But the point is more general, going all the way down to the constitution of subjectivity itself. In the state of nature there is no genuine subjectivity, just the 'natural solipsism' of animals (Williams, 1997: 50). Only through recognition can people acquire and maintain a distinct identity. One becomes a Self, in short, via the Other - subjectivity depends on inter-subjectivity. Insofar as people want to be subjects, therefore, they will desire recognition of their difference.

Desires for recognition can take various forms, which I will group into 'thin' and 'thick', both of which are potentially relevant to world state formation. ${ }^{51}$ Thin recognition is about being acknowledged as an independent subject within a community of law. To be recognized in this way is to have the juridical status of a sovereign person rather than an extension of someone else (like a child or slave), and thus to be a legitimate locus of needs, rights and agency - a subject rather than an object. These rights are nevertheless 'thin' because they acknowledge nothing more about an actor's particularity other than the simple fact of difference, and so everyone who has this status is essentially the same, a 'universal person'. In contrast, thick recognition is about being respected for what makes a person special or unique. Like thin recognition it constitutes a mode of subjectivity, and with 
it legitimate difference, but the difference is particular rather than universal. As such, there is no limit to the forms that demands for thick recognition might take - from pursuit of virtue, success, Great Power status, to being God's chosen people - which means that struggles for thick recognition are open-ended and never-ending in a way that struggles for thin recognition are not. True, the former will only be relevant to state formation if they take the form of demanding legal rights enforceable by the state (or, alternatively, constitute grounds for secession if they are not met), but by the same token it seems impossible to stipulate ex ante which kinds of thick recognition might take that form. Fortunately, this lack of specifiable content is not a problem here, since what matters to world state formation is only that the struggle for thick recognition be 'domesticated' over time - in the sense of accepting non-violence and the authority of the state - whatever its particular objective might be.

Perhaps paradoxically, if the desire for recognition is about being accepted as different, the effect of mutual recognition is to constitute collective identity or solidarity. The starting point for this claim is that by recognizing the status of the Other and accepting the normative constraints on the Self which that implies, one is making the Other part of the Self - she is no longer purely 'Other'. When recognition is reciprocal, therefore, two Selves in effect become one, a 'We' or collective identity (Williams, 1997: 293) not in their entirety, but with respect to the status at stake in their mutual recognition. Consider the mutual recognition of sovereignty by European states in 1648. It constituted each as a distinct subject with certain rights, but also constituted them collectively as members of a 'society of states' bound by certain rules, and willing to defend those rules jointly against nonmembers like the Ottoman Empire (cf. Neumann and Welsh, 1991). To be sure, they might have created this structure for self-interested reasons, and so in saying that mutual recognition constitutes a collective identity I am not suggesting that the latter will necessarily be felt right away. But a collective identity is nevertheless immanent in mutual recognition, since the modes of subjectivity that it constitutes are dependent on Others; Westphalian states would not have the rights they do but for the society of states. Once this dependency on the group is appreciated we can expect mutually recognizing actors to exhibit solidarity toward the group qua group. In short, two actors cannot recognize each other as different without recognizing that, at some level, they are also the same (cf. Brewer, 1991).

The Instability of Asymmetric Recognition. The desire for recognition is about getting recognition from the Other, not about giving it to the Other. As such, the desire can in principle be satisfied either symmetrically or asymmetrically - by recognition of the Other's equality, or by securing his 
recognition of the Self without reciprocating it. For Hegel, a properly formed state is constituted by mutual recognition of equality, which goes beyond Weber's mere monopoly of legitimate force. This reflects Hegel's teleological view that the end of the state is not just to protect its members' physical security, but to make their subjectivity possible, which cannot be fully realized until all are recognized as equal and an impartial judge exists to enforce this status against criminals (Baynes, 2002: 6). In such a state the desire of all actors for recognition is satisfied, and we can therefore expect it to be highly stable.

Asymmetric recognition is less stable, and central to my subsequent argument. It can take various forms, from the extreme of slavery, in which there is no recognition of one party at all (slaves are mere appendages of masters), to more subtle forms like ancien regime France, in which recognition is mutual but unequal (peasants have some subjectivity, but less than nobles). But what all such hierarchies share is that one actor satisfies its desire for recognition by denying full recognition to another (Fukuyama, 1992: 163, 182). In a hypothetical world where anything was possible, being the dominant party in such a relationship might be an actor's first choice, since recognition means accepting limitations on the Self. This suggests a basis in recognition theory for the belief of some realists that human beings are driven by a will to power (Nietzsche, 1989) or animus dominandi (Morgenthau, 1946). ${ }^{52}$ By the same token, however, those who are not fully recognized will struggle for it as best they can, which makes any social order founded on unequal recognition unstable in the long run.

The sources of instability are both material and ideational. Materially it can be costly to suppress desires for recognition. If people are denied something of fundamental importance to themselves their acceptance of a regime is likely to be half-hearted and dependent on coercion, which even Hobbes recognized was a less efficient and stable basis for order than legitimacy. Of course, in a given historical conjuncture even people who are not recognized may perceive a regime as legitimate (more in a moment), but once their desire for recognition is activated into resistance stability will be costly to maintain. And on the ideational side there is also a long-term threat, rooted in the logic of recognition itself. Even though A's desire to be recognized by $\mathrm{B}$ is not in itself a reason for $\mathrm{A}$ to reciprocate, Hegel argues that recognition based solely on coercion - his example is the master-slave relationship - is ultimately unsatisfying, because the failure to recognize the slave calls the master's own subjectivity into question. ${ }^{53}$ Recognition is only valuable if it comes from someone perceived as having worth and dignity, and since the slave is not his recognition of the master is ultimately 'worthless' (Williams, 1997). Thus, in the long run the only way to secure 
fully stable recognition from the Other is to reciprocate it. In Hegel's view this is a precondition for freedom. One can only be free if recognized as such, and that recognition is only valuable if it is freely given. ${ }^{54}$

On the other hand, the fact that unequal recognition may be costly or ultimately worthless does not mean that it cannot appear highly stable, and even legitimate in the eyes of subordinate actors. Indeed, historically this is precisely what we observe, unequal political orders - 'non-Hegelian Weberian states' - that survived for long periods of time. However, if we consider the sources of stability in such orders we can see that this does not militate against the transformative power of the struggle for recognition.

At the micro-level, recognition is not the only desire at work in the system - physical security is another, which may induce actors to put their lives before recognition..$^{55}$ It might be thought that security is more fundamental, on the grounds that one cannot enjoy recognition if one is dead. But the desire for recognition doesn't work that way. As a precondition for genuine subjectivity recognition is part of what makes security worth having in the first place, and people will often sacrifice their lives for it. Suicide bombers are the extreme case, but it seems hard to explain anyone's willingness to fight in a war or participate in a revolution without appealing to the desire for recognition. On the other hand, it is equally clear that people often will not risk their lives for recognition. In Nietzsche's (1989) view this is the choice made by the slave, which he therefore saw as characteristic of the 'slave morality'. ${ }^{56}$ So my claim is only that the desire for recognition is on par with security, not that it always trumps. In addition, there is the factor of hegemony and false consciousness. People might have been socialized to think they do not deserve recognition, or that it is unthinkable for someone in their position. However, this does not mean that people do not fundamentally want it. The need might not be subjectively perceived, but it could still be an objective interest (Wendt, 1999: 231-3), which, when activated will motivate actors to struggle for it. The possibility of hegemony, in turn, points toward the role of macro-level structures of physical and social power in stabilizing unequal recognition. States are homeostatic systems that exert downward causation on their members. This disciplines people to obey the state most of the time of their own accord, and authorizes violence by state agents when they don't. If we add to this the collective action problems facing would-be revolutionaries, it is clear that even if people actively want recognition they may be unable to challenge the stability of an unequal system in a given historical conjuncture. What I need to show, therefore, is not that desires for recognition never encounter resistance or are always successful, but that in the long run they undermine systems that do not satisfy them. 
Individual and Group Recognition. Given that historically human beings have always been organized into autonomous groups, the struggle for recognition is not just about recognition as an individual in the abstract, but as a member of a particular group. Such recognition is a constitutive aspect of individual identity, since it is through groups that individuals acquire subjectivity. Attachment to groups, manifested today in nationalism, is a reflection of this fact. People do not easily shed group loyalties even if other groups are available as substitutes. This 'embeddedness' of individuals within groups is a key principle of communitarianism (Sandel, 1982). Liberals are more ambivalent. Probably speaking for many liberals, Fukuyama (1992: 201) argues that deep attachments to collective identities like the nation are 'irrational'. Yet, in that case it is puzzling for him that history will end in a world of sovereign states. If history is an unfolding of Reason, why would it stop before such irrational attachments had been overcome? On the other hand, some liberals have accommodated a constitutive role for groups in individual identity (Tamir, 1993; Kymlicka, 1995; Linklater, 1998). Like communitarians, they see group attachments as both natural and normatively valuable.

The fact that human beings have attachments to different groups has two important implications for struggles for recognition. First, within the system as a whole people confront each other not only as individuals but as members of groups, and so the struggle for recognition is mediated by group boundaries. This is true both within and between groups. Internally, group boundaries mean that those from whom recognition is sought, at least initially, are merely other members of the group, not individuals everywhere. Indeed, a distinction between members and non-members is often constitutive of domestic recognition struggles, since participation in a privileged status vis-à-vis outsiders may be one reason that insiders seek recognition in the first place. Externally, in turn, group boundaries mean that even once the struggle for recognition is 'over' within a group, members will still face the problem that people in other groups do not recognize them. Territorial state sovereignty, in other words, is by its very nature a structure of unequal recognition. As a result, outsiders are denied rights and may even be killed not because of what they have done as individuals, but simply because they are members of a different group. In that respect the members of sovereign states suffer a 'common fate' (Wendt, 1999: 349-53). This may have little salience for individuals as long as their state can protect them from war, but as long as war is a possibility their recognition will be incomplete.

Second, like individuals, groups too have a desire for recognition, in this case corporate recognition. This desire exists only in virtue of their members' desires to secure the conditions for their subjectivity, but because those conditions involve common fate, if a group's subjectivity is not 
recognized by other groups, then its members will not be recognized either. To that extent groups' desire for recognition is irreducible to the desire for individual recognition (see Wendt, 2004). Again, note that this does not mean that groups seek a world state. What groups want is for Others to recognize them, not necessarily to recognize Others. Nor does it mean that groups are forever unchanging. Group identity is a process not a thing, and its transformation into larger collective identities is precisely what begins to happen through mutual recognition. But just as the willingness of individuals to participate in a collective identity ultimately depends on their recognition as separate individuals, so too would groups entering into a larger identity want their difference recognized. Universalism, in short, depends on recognition of particularism. ${ }^{57}$ World state formation is not only a cosmopolitan process, but a communitarian one as well.

The struggle for recognition, then, operates on two levels simultaneously, between individuals and between groups. If we add to this the fact that some inter-group struggles today are taking place within states (as in sub-state nationalism), and some inter-individual struggles are taking place on the global level (as in global civil society), we have a hugely complex picture, with many cross-cutting relationships. On the other hand, my argument is that these are all part of a single systemic logic. In order to highlight that logic in what follows I shall make two simplifying assumptions - (1) struggles for recognition within states, whether by individuals or groups, can be bracketed; and (2) the units in struggles for recognition at the system level are initially states. The first assumption does not imply that domestic struggles for recognition are over, or that they will not affect the process by which the global struggle for recognition unfolds - for example, by breaking up existing states (Walzer, 1986). The point is only that because the system's telos is multiply realizable at the micro-level, the details of domestic struggles do not affect its eventual end-state. The second assumption is justified by the facts that the system has always consisted of autonomous groups which constrain inter-individual struggles across group boundaries, and those groups today are states. Despite this state-centric starting point, however, individual desires for recognition will emerge to play a crucial role in the system's development.

\section{The Logic of Anarchy}

The struggle for recognition is the bottom-up aspect of the argument. I now turn to its top-down aspect. I argue that the process of world state formation progresses through five stages of recognition, the first four constituting distinct cultures of anarchy (cf. Wendt, 1999). Each culture imposes boundary conditions that increasingly constrain the interactions of the 
system's parts, but in so doing enable growing subjectivity and freedom at the global level. What drives the system forward is the logic of anarchy, which through downward causation conditions struggles for recognition in two ways - by making it possible to seek recognition through violence, and by generating improved military technology that makes such violence increasingly intolerable. These growing costs break down the self-sufficient state identities in Hegel's story, enabling states to develop supranational Wefeeling and thereby overcome what he sees as the fundamentally tragic character of their struggle for recognition (Williams, 1997: 257-63). Each culture of anarchy is a relatively stable stage in this process, forming a local attractor in the system's development. However, all stages short of the world state are unstable. New stages with more demanding boundary conditions emerge as solutions to instabilities in the stage before it ${ }^{58}$ but in turn bring about new instabilities that require further elaboration for their resolution. In short, the logic of anarchy transforms structures of recognition and identity from a territorial to a global basis, giving us a Weberian world state by creating a Hegelian one.

What follows is a conceptual rather than historical argument, in the sense that the proposed stages refer less to a necessary temporal sequence than to logical problems of recognition that must be solved for a world state to emerge. I have ordered these problems chronologically because solutions to the 'earlier' problems seem to have fewer preconditions than the later ones, and as such are likely to be discovered by the system first, but that does not preclude the possibility of skipping stages or solving several problems at once. Moreover, the proposed progression of stages is compatible with backsliding in a given historical moment. The argument is not linear; it claims only that any step backwards will eventually be balanced by two steps forward. With those qualifications in mind I take up each stage in turn.

\section{Stage One: The System of States}

This is the stage of complete non-recognition, what Hobbes called the 'warre of all against all' and Bull (1977) a 'system' of states. This system is constituted by three boundary conditions - the fact of multiple interacting states (individuals are not actors at all here), or simple difference; the absence of any mechanism to enforce cooperation among these states (anarchy); and a mutual belief that they are 'enemies' (Wendt, 1999: 260-3), with no rights and thus social constraints on what they may do. Because there is no recognition there is no perceived collective identity in the system, and by implication states do not even have genuine subjectivity. Insofar as states share an awareness that they are in a Hobbesian system it 
will constitute a culture, but this culture and its implicit collective identity will be 'repressed' (Wendt, 1999: 278).

The Hobbesian stage is unstable in the long run because it does not begin to meet needs for recognition. Taking the dyadic case first, we can see this instability and its developmental consequences by considering the two possible outcomes of a struggle for recognition in such a system. One, which we would expect if one state is significantly stronger than the other, is the conquest of the weaker state. The dyad becomes a single unit, and the locus of self-organization then shifts to the interaction of this enlarged state with other states. ${ }^{59}$ If success begets success and conquests continue, eventually only one state will be left, and the system will no longer be anarchic. Such an outcome might even come to be seen as legitimate by its subjects and thus be stable for some time. However, if the conqueror does not recognize its victims then they will eventually try to break away, thereby recreating an anarchic system. In other words, a Weberian world state that is not also a Hegelian one - an 'empire' - will be unstable in the long run. On the other hand, if the world conqueror does turn around and recognize its victims as full subjects, then a stable world state will have been achieved without the intermediate stages of development.

The second possible outcome would occur if the two states are equal in power. In that case neither can conquer the other, and they will continue to struggle for recognition. This need not involve constant warfare, but will require constant preparations for war that drain societal resources, and war will remain a significant probability. This dynamic too is not stable. Either one side will eventually get the upper hand and conquer the other, or they will 'wear each other out' (Burbidge, 1994: 157) to the point that they realize that continued struggle is pointless, and agree to mutual recognition. The effect of anarchy on military technology is important here, since over time it will increase the cost of war, and with it negative feedback on a policy of non-recognition. Conversely, mutual recognition would create positive feedback, since it would allow competitors to devote more resources to other purposes, including struggles with third parties. This may be seen as a stylized account of the process that led to the Peace of Westphalia, and one might expect a similar outcome in, for example, the Israeli-Palestinian conflict today.

Whichever outcome transpires, therefore, a Hobbesian anarchy is unstable in the long run, and will eventually move toward a non-Hobbesian attractor. In principle that could be any of the remaining developmental stages mentioned later, including a world state. However, so that I can detail the entire logic let's assume that the system can only solve one developmental problem at a time. 


\section{Stage Two: The Society of States}

The instabilities of the Hobbesian culture can be resolved by moving to a 'society of states' (Bull, 1977) or Lockean culture of anarchy (Wendt, 1999). In this culture states recognize each other's legal sovereignty as independent subjects, but not that of each other's citizens. This implies an acceptance of certain constraints on state action, but makes possible a corresponding measure of positive freedom and subjectivity that does not exist in the Hobbesian world. There is also the emergence of some solidarity among states - they see themselves as a 'We' bound by certain rules - that provides a resource for limited cooperation. On the other hand, the depth of this collective identity remains shallow, and in particular, limited war remains acceptable. War may not be used to conquer other states, but is still legitimate for purposes of territorial or other gain - what John Ruggie (1998: 162-3) calls 'positional' as opposed to 'constitutive' wars. Thus, while states no longer constitute each other as 'enemies', they still do so as 'rivals' (Wendt, 1999: 162-3). This generates two sources of instability.

First, even though positional wars do not threaten states' 'lives', they can still be costly, and these costs will rise over time with secular improvements in military technology. Today, even conventional wars between equal states can be enormously destructive, and will be only more so in the future, a fact which may help explain their contemporary rarity.

Second, even if states don't get 'killed' in positional wars, people do. As such, as in the Hobbesian culture, here too individuals are not recognized outside their own state, and thus as subjects in the world system. Individuals do not like dying in war, especially when their group identity is already at least minimally recognized by other states. Given the importance of group identity to individuals, sacrifice in war makes sense in a Hobbesian culture, since people are fighting for individual recognition as well. But in a Lockean culture states have gained some recognition, and so it is less clear how sacrifice for the state would meet individuals' needs. Over time we can expect individuals to make those needs apparent to their leaders, inducing the latter toward growing caution in the use of force as a tool of diplomacy, particularly as the costs of war rise. Eventually, through this pressure from below states in a Lockean culture will learn to desist from war altogether, and to find non-violent means to solve foreign policy problems (at least among states that are similarly reluctant to go to war). What we see here is the emergence of individuals' struggle for recognition alongside that of states as a force at the system level. The problem of war means that individual recognition must be external as well as internal, which requires breaking down its mediation by state boundaries. 
This narrative of instability is similar to the logic of the 'democratic peace', in which the reluctance of individuals to die for their country helps pacify relations among democratic states. However, it is not clear that my story depends on democracy at the unit-level. Such states may be sufficient for translating individuals' desires for recognition into inter-state peace, but we do not know if they are necessary. ${ }^{60}$ Since what matters to the argument is only that individuals' desire for recognition by outsiders be somehow realized, it seems wise at this point to leave open exactly how this would be accomplished at the domestic level.

If a Lockean culture is not a stable end-state, then in what direction will the system go? One possibility is to descend back to a Hobbesian culture, as we saw in World War II. But even if the Axis had conquered the world, this would have merely set the stage for subsequent forward movement. Either the conquered peoples would have revolted, dismembering the Axis empire and restoring the logic of anarchy, or the Axis would have recognized them, constituting a world state. So even if the system backslides temporarily from its developmental path, the instabilities of the Hobbesian culture mean that eventually it must come back to the Lockean culture and its primary source of instability - war - which can only be resolved by moving forward.

\section{Stage Three: World Society}

The immediate problem of war is solved by creating a universal pluralistic security community, which adds the requirement of non-violent dispute resolution to the boundary conditions of the system. Mutual recognition at the system level now begins to extend to individuals as well as states, making it analogous to the recognition found in fully formed territorial states. As such this stage might be called a cosmopolitan or world society. The system has now constrained the liberty of its parts even more (they are no longer free to make war), but in so doing has developed a thicker form of solidarity than a society of states, which expands positive freedom for both individuals and states.

Yet, this developmental stage too is not a stable end-state, because of the absence of collective protection against aggression. Even if everyone today is committed to peaceful dispute resolution, there is always the possibility in the future of rogue or 'criminal' states emerging through domestic revolution, which reject non-violence and attack other members of the system (cf. Mearsheimer, 2001). In principle there are two ways to deal with this problem, neither of which is available in this culture. One is by centralized coercion. That is unavailable because in a world society states retain sovereignty. The other is decentralized enforcement by a collective security system. That is unavailable as well, because a security community is 
compatible with states being indifferent to each other's fate; it imposes no requirement of mutual aid. A state threatened by a rogue could therefore not be certain others would defend it against aggression. To sustain a world society actors need a more demanding form of recognition, one that imposes not only negative duties (non-violence) but also positive ones (mutual aid).

Where does the system go from here? There is always the possibility of degeneration back to Stage Two or even One, but as we saw earlier those outcomes are not stable in the long run, and so will only bring us back to Stage Three again. Conversely, there are good reasons to move forward toward a commitment of mutual aid. Consider a system of three states, A, B and $\mathrm{C}$. If $\mathrm{A}$ and $\mathrm{B}$ form a security community they will both experience positive feedback - no fear of war, at least on one flank; less need for costly arms; and recognition of both group and individual subjectivities. A and B will be reluctant to give these benefits up, and so once peace has been achieved they will have an interest in its being perpetual. Now let $\mathrm{C}$ become an existential threat to B (only). This would create the possibility for A that a previously peaceful border would be occupied by a hostile state, plunging the border back to a state of war. That gives A an interest in helping $\mathrm{B}$, even though $\mathrm{A}$ is not directly threatened. ${ }^{61}$ In effect, the anticipated negative feedback of its neighbor's demise sustains the positive feedback provided by their peaceful relationship. Since these incentives are mutual, both have reason to care about each other's fate, and form a permanent alliance. This does not mean that states will always recognize these benefits, but those that do deepen their solidarity will have a better chance of survival than those that do not, suggesting that in the long run they will colonize the system (Cusack and Stoll, 1994; Cederman, 2001). ${ }^{62}$ Once the system reaches the stage of world society, therefore, the desire to reproduce it will induce it to develop even farther.

\section{Stage Four: Collective Security}

At this stage the system acquires an additional boundary condition: not only must its members - now both individuals and states - recognize each other's sovereignty and practice non-violent dispute resolution, but they are expected to defend each other against threats on the principle of 'all for one, one for all'. The system has now reached a 'Kantian culture' of collective security or 'friendship' (Wendt, 1999: 298-9). Actors have a well-developed sense of collective identity with respect to security, such that each sustains its difference by identifying with the fate of the whole. Although today we are far having from such an identity on a global scale, its benefits have already been demonstrated at the regional level. The ease with which the US was 
able to put together coalitions to fight the first Gulf War and the War on Terrorism, the persistence of NATO after the end of the Cold War, and even the Concert of Europe (Schroeder, 1993; Mitzen, 2001) are all best explained by perceived common fate. In all these cases mutual recognition had positive rather than just negative behavioral requirements.

However, a universal collective security system is not a world state. Territorial states retain their sovereignty, and as such its functioning depends on their consent. A collective security system cannot require its elements to continue recognizing each other, in the sense of commanding a legitimate monopoly of force to enforce it. The system is voluntary in a way that a state is not. Strictly speaking, it remains anarchic. On the other hand, given that collective security seems to meet both individual and group needs for recognition, and has some ability to enforce that recognition, it is not immediately clear why anything more is needed.

The difficulty is felt by Kant, whose teleology stops at the pacific federation, and if Fukuyama is representative this is also where contemporary liberals end up. In fact Kant shows more ambivalence on this score than is sometimes thought. In 'Idea for a Universal History with a Cosmopolitan Purpose', he seems to endorse giving the federation enforcement powers that would significantly qualify the sovereignty of its members. However, later in 'Perpetual Peace' he comes down more clearly on the side of a purely consensual system, with no coercive power at the supranational level (although suggesting that this is a 'second-best' outcome). ${ }^{63}$ Kant's skepticism about a world state is threefold - it is not feasible to enforce political authority on a global scale; states will not give up their sovereignty to a world state; and a world state would be despotic. Drawing on Deudney, I have already addressed the first concern - technological changes since the 18th century have made it possible today to project coercive power on a planetary scale. But the other concerns remain, seeming to indicate that the development of the system would stop with universal collective security.

An argument for the inevitability of one more stage must begin with the instability of collective security as a solution to the struggle for recognition. Perhaps the most commonly adduced instability, usually emphasized by Realists, is that collective action problems make collective security inadequate as a deterrent to aggression; when it is most needed it is most likely to fail. While this problem has some force, it points not toward a world state but to the degeneration of anarchy back to a Lockean culture, if not to the war of all against all. Moreover, the Realist argument presupposes that states remain self-interested egoists, which is undercut by the kind of collective identity formation that I have argued would accompany the development of a collective security system. However, two other sources of instability are not so easily handled. 
First, because collective security is a consensus-based system in which states retain their sovereignty, it would have no right to prevent a state from seceding and then arming itself for aggressive purposes (Carson, 1988: 179-80). Kant tried to deal with this problem by calling for voluntary disarmament, but even if that were successful it does not solve the problem of possible rearmament in the future (cf. Mearsheimer, 2001). Second, and more importantly, collective security does not fully satisfy desires for recognition. For what, in the end, is the retention of sovereignty if not retention of the right to decide, unilaterally, to revoke an actor's recognized status and possibly kill them? A state might promise not to exercise this right, and even keep that promise for a long time. But as long as the right to kill is not permanently surrendered to an authority with the capability to enforce recognition, Others will remain vulnerable to a change of policy by the Self. These problems suggest that a collective security system would not be a stable end-state. But we still need an argument for why this would lead to a world state rather than back to more primitive forms of anarchy. Three considerations suggest themselves.

One is a collective memory of what anarchy was like before collective security, which with the experience of World Wars I and II has been an important source of European integration (Waever, 1995). True, collective memories imply a 'collective', and today collective identities are much thicker at the regional than global level. But rising interdependence is deepening collective identity at the system level, and when coupled with the rapid growth of transnational publicity, truly global memories, such as $9 / 11$, are becoming possible for the first time. Further painful global memories in the future - a regional nuclear war? - could therefore be a source of universal integration. Much like Hobbes' retrospective argument for the state, these memories would constrain the system's degeneration, making a move back toward anarchy less attractive than a move forward to a world state.

A second factor is that if states have formed a deep enough collective identity to defend each other even when they are not themselves threatened, then de facto they do recognize obligations to each other and their citizens, and the de jure issue is moot. The only reason not to make recognition binding - to constitutionalize it - is to leave open the possibility of changing their minds, but that seems hard to square with a genuine commitment to universal recognition. Here Hegel's argument that unreciprocated recognition is ultimately unsatisfying may come into play. The kinds of actors most likely to be vulnerable to such dissatisfaction are precisely those found at this stage of history - ones whose self-conception is that of civilized, law-abiding actors who believe that all individuals and groups should be recognized. More than most, such actors would be 
susceptible to the 'civilizing force of hypocrisy' (Elster, 1995), and so find it hard in the long run to justify not constitutionalizing their recognition of outsiders.

However, while removing constraints on world state formation, these first two considerations are still in a sense negative, since they amount to reasons not to resist the attraction of a world state, not to embrace it. A third factor is therefore crucial - the struggle for recognition itself. Recognition that is not enforceable is in the end not really recognition at all, since it depends on the goodwill and choice of the recognizer. Genuine recognition means that the recognized has a right to recognition, and the Self therefore has a duty to the Other. Genuine recognition is about obligation, not charity. Only when acting on behalf of the Other has become an enforceable obligation is recognition secure.

This point becomes particularly salient for the Great Powers, who are arguably the greatest hurdle to world state formation. The struggle of individuals and Small Powers for enforceable recognition is not particularly puzzling, since their weakness makes them vulnerable to the strong. They have little to lose from making mutual recognition of equality accountable to a world state, and as such they are the principal engine in the system's development. The Great Powers are in a different position - less vulnerable than other actors, able to enjoy unprecedented wealth as a result of their sovereign right to restrict immigration, and able to treat other states as they see fit. In effect, 'go it alone power' means they can afford not to learn, at least in the short run, that it is only by constitutionalizing their obligations to Others that their own subjectivity can be guaranteed (Wendt, 1999: 331; Gruber, 2000). The current resistance of the US to binding multilateral commitments is symptomatic of the problem. What could Great Powers gain by joining a world state?

It is a good question, but consider what would happen in the long run if Great Powers insist on retaining their sovereignty. For the reasons discussed above, a non-binding collective security system is not a stable end-state. As such, we can expect individuals and Small Powers to continue pressing for recognition, and as their violence potential grows through the diffusion of more destructive weapons they will be able increasingly to threaten the Great Powers (think North Korea here, or al-Qaeda). Small and Middle Powers will also have good reasons to federate, creating new Great Powers that can 'balance' existing ones, and perhaps setting in motion arms races. In such conditions the ability of Great Powers to insulate themselves from global demands for recognition will erode, making it more and more difficult to sustain a system in which their power and privileges are not tied to an enforceable rule of law. It may take some time for Great Powers - and perhaps especially 'hyper-powers' like the United States - to see the light. 
But if the choice is between a world of growing threats as a result of refusing to fully recognize Others versus a world in which their desires for recognition are satisfied, it seems clear which decision rational Great Powers should make.

\section{Stage Five: The World State}

This brings us to the world state. With the transfer of state sovereignty to the global level individual recognition will no longer be mediated by state boundaries, even though as recognized subjects themselves states would retain some individuality (particularism within universalism). Individuals and states alike will have lost the negative freedom to engage in unilateral violence, but gained the positive freedom of fully recognized subjectivity. The system will have become itself an 'individual' (Buss, 1987).

The question remains, however, whether a world state would be a stable end-state, or be itself subject to instabilities that ultimately undo it. In other words, even if we assume that the logic of anarchy is teleological, how do we know that it involves a fixed-point attractor rather than, for example, a periodic attractor that would induce cycles of anarchy and world states?

A partial answer is that a world state would have the capability to prevent secession, giving it a stronger homeostatic logic than any culture of anarchy. However, coercion alone does not seem enough, since individuals and groups will continue to evolve, and might decide that what satisfied their desires for recognition in the past no longer does so. Efforts to crush such aspirations by force have not prevented some existing states from breaking up, and imposing recognition by force is in any case at odds with the basic principle that recognition that is not freely given is not really 'recognition' at all. At most, therefore, the ability to prevent secession would ensure temporary security, not recognition.

In thinking about whether the logic of anarchy has a fixed-point attractor, it is important to emphasize this need not imply that a world state must survive for ever. Equilibria are always vulnerable to exogenous shocks. Since even a world state would remain an at least partially open system, such shocks could cause it to fall apart. Instead, for the logic of anarchy to have an end-state other than a fixed-point attractor, there must be something internal to the system itself that would necessarily induce an eventual collapse, sending it along another developmental path. Addressing this question permits consideration of three objections to my argument, each of which highlights a potential endogenous source of instability in a world state. $^{64}$

The first is Kant's worry about despotism. Could a world state be despotic? If a world state met only the thin Weberian criterion of a legitimate 
monopoly of force, then in principle it could be despotic, an 'empire'. But in that case it would not be a stable end-state, since it would not satisfy the thicker Hegelian criterion of mutual recognition of equality. In such a state the struggle for recognition would go on. Since my argument is that we will get a Weberian world state by creating a Hegelian one, the real question is whether the latter could be despotic, which seems unlikely. The most obvious threat is a 'democratic deficit' (e.g. Wolf, 1999). The sheer scale of a world state and the corresponding dilution of voice for its members would create a huge distance between them and the state (Dahl, 1994). Although today's worries about the democratic deficit stem primarily from the absence of virtually any formal means by which transnational power structures can be held accountable, they are already a source of resistance to political integration and might intensify as the latter deepens.

On the other hand, large democracies today already face this problem, yet are not for that reason considered unstable. Modern communications technology and institutional compromises like representative democracy and subsidiarity can mitigate democratic worries to a substantial degree. But the real lesson of modern states is that democracy is not the only basis of political legitimacy. The enforcement of mutual recognition of equality, economic well-being and efficiency may be equally important, and could be even more so in a world state. Moreover, consider the alternative to a world state, an anarchic world in which territorial states retain their sovereignty. It is of the essence of sovereignty that power and violence can be exercised against non-members without any accountability. Is not that 'despotism' (Tamir, 2000: 263)? Whether justified or not, to whom is the United States accountable for its recent killing of thousands of civilians in Kosovo, Afghanistan and Iraq? Whatever the accountability problems in a world state might be, they seem far less than those in anarchy.

A second potential threat is nationalism, which in the last century has substantially increased the number of states in the system through decolonization, thus at least temporarily reversing the historical pattern of global political consolidation to which Carneiro (1978) points. However, the rise of nationalism can actually be seen as evidence for my argument, because it is about the struggle for recognition. In 1945 a majority of the world's population lived in empires that did not recognize them as full subjects. As a result they struggled for self-determination and eventually won it. In that sense nationalism has made it possible for previously unrecognized actors to participate in the system, and even contemplate binding themselves to supranational institutions. Any such constraints they accept will be consensual and correspondingly stable. Nationalist struggles for recognition are not over, and more new states — 'more anarchy' — may be created. But while further fragmentation is in one sense a step back, it is 
also a precondition for moving forward, since it is only when difference is recognized that a larger identity can be stable (Walzer, 1986). 'The greater the diversity between individuals or particulars, the higher the identity or universal in which the differences meet'. ${ }^{65}$ Far from suppressing nationalism, a world state will only be possible if it embraces it.

A last potential source of instability in a world state involves what might seem like a contradiction at the heart of my analysis. On the one hand, like today's states I am arguing that a world state would be a subject - a corporate persons or Self. On the other hand, my explanation for the inevitability of a world state assumes that a stable Self depends on mutual recognition of equality with an Other. By assimilating all subjects into one collective identity, a world state would seem to lack such an Other and thus be unstable. Barring an extra-terrestrial Other (cf. Harrison, 1997), how is this global Self to sustain its subjectivity? Who, in short, recognizes the world state?

Recognition presupposes an axis of differentiation between potential subjects. This suggests a two-part answer to the question. First, the world state would be recognized by the individuals and groups that constitute its parts, and it in turn would constitute and recognize them. This is possible because even though parts and whole are mutually constitutive, they are not identical; there is a boundary or difference between them. The members of a world state have their own subjectivities that constrain its behavior, and the world state has a subjectivity that constrains their behavior. This internal differentiation allows each to recognize the Other, while incorporating that Other within its own definition of Self. Such a process goes on every day within today's territorial states. However, this comparison also highlights an important difference between the two cases, which is that in territorial states the struggle for recognition assumes a spatial boundary between members and non-members. Insiders form their sense of Self not only in relation to each other, but through practices that differentiate them from outside Others. Since a world state would be global, it would not have such an external Other available to it, which might be thought to undermine its subjectivity.

That leads to the second part of the answer - a world state could compensate for the absence of spatial differentiation through a temporal differentiation between its present and its past (cf. Ruggie, 1993; Waever, 1995). The past here is anarchy, with all its unpleasantness. In Hegelian terms we could say that 'history' becomes the Other in terms of which the global Self is defined. Of course, this Other does not have a subjectivity of its own, and so cannot literally recognize the world state. But a functional equivalent to recognition can be achieved by an act of temporal selfdifferentiation. Whether at the individual or collective level, identities are 
always constituted by narratives (Ringmar, 1996), in which a present identity is legitimated in relation to a past (and often a future as well). Sometimes, as in many nationalist narratives, this process interprets the present Self as identical to an imagined past Self. Other times, however, collective narratives draw a distinction between past and present identities. Germany today, for example, constitutes its identity in part by its difference from the Nazi state. Temporal self-differentiation makes mutual constitution possible, thereby enabling 'an Other' to stabilize the global Self.

That stability raises a final question - what happens after the world state is reached? Do politics and history come to an end? If by 'politics' and 'history' we mean what they do in anarchy, namely struggles for recognition mediated by war, then yes, in one sense they would be over. I say in one sense' because a world state would still need to reproduce itself and thus be for ever in process, and since even a world state would not be a closed system it will always be vulnerable to temporary disruptions. However, a world state would differ from anarchy in that it would constitute such disruptions as crime, not as politics or history. The possibility of crime may always be with us, but it does not constitute a stable alternative to a world state. Moreover, politics or history in a different, non-anarchic sense would clearly not be over. A world state would not be a utopia in which there was nothing left to struggle over. Think of what goes on inside states today. They are full of problems - crime, poverty, pollution - which are the stuff of politics. Indeed, even struggles for recognition, in the thick sense, would continue. There are always new ways to constitute thick recognition, and in that sense the struggle for it is part of the human condition (Honneth, 1996: 126-7; Bauman, 2001). But once a world state has emerged those struggles will be domesticated by enforceable law, and so for purposes of state formation will be no longer important. Rather than a complete end of history, therefore, it might be better to say that a world state would be the end of just one kind of history. Even if one telos is over, another would be just beginning.

\section{Conclusion}

Against the perpetual war of Realism and the contingent perpetual peace of modern liberalism, I have argued that a world state is inevitable. Its cause is the teleological logic of anarchy, which channels struggles for recognition toward an end-state that transcends that logic. As such, the argument reverses social scientists' traditional 'rearview mirror' perspective on time and causation (Wendt, 2001), since it suggests that 'the ultimate organizing principle [of the system] is in the outcome of the process and not its genetic origin'. ${ }^{66}$ One might even say that the logic at work here is that of 
recognition, not anarchy, since only a world state can realize or complete the mutual recognition of sovereignty first laid down in the society of states.

It is natural at this point to ask whether a world state would be desirable. Although this question is not directly relevant to my argument and cannot be addressed here (see Tamir, 2000; Griffin, 2003), on my view the answer is clearly yes. Other things being equal, it seems hard to argue that a world in which recognition is unequal and the right to engage in organized violence is privatized would be normatively superior to one in which recognition is equal and violence is collectivized. That does not mean that a world state would satisfy all the demands of justice, but it would be a minimum condition for a just world order.

I have argued that a world state will emerge whether or not anyone intends to bring it about. Since this might be criticized for leaving out human agency, by way of conclusion I want to show that this is not the case, at either the micro- or macro-level.

At the micro-level agency matters just as much here as it does in nonteleological theories. Struggles for recognition are intentional, and there is nothing in the logic of anarchy that forces them to go in one direction or another at any given moment. Anarchy is (still) what states (and other actors) make of it, and so they are still responsible for the quality of life in world politics. Moreover, in addition to the intentionality of actors struggling for their own recognition, there is also the possibility for a more globally oriented intentionality in the form of actors who believe in the inevitability of a world state, and try to speed it up. To be sure, this kind of agency is a double-edged sword. On the one hand, belief in an inevitable world state would give people reasons to intentionally redefine their interests in terms consistent with it, thereby facilitating the process. On the other hand, such a belief could also be used to justify forcing history along, and even for war against those who refuse to see the light. Some of the worst historical excesses of human agency - Nazism, Bolshevism, and so on have been committed in the name of just such a teleological faith. But such is the human condition - the fact that the pathway to a world state is open to such possibilities is an argument for more 'good' agency, not less.

Moreover, my argument has an interesting policy implication for grand strategy. Grand strategies should be based on a correct theory of where the world system is going. If Realists are right that anarchy is programmed for war, then it makes sense to define one's sovereignty and interests in egoistic terms and act on that basis. International law is irrelevant or an impediment to the national interest, and one should pursue a unilateralist policy whenever possible. On the other hand, if a world state is inevitable (and, importantly, not so far off to be meaningless for policy), then a different grand strategy emerges. Rather than go down with the ship of national 
sovereignty, states should try to 'get the best deal' they can in the emerging global constitution, which counsels acceptance of international law and participation in multilateral institutions. Ironically, if a world state is inevitable, states that pursue such policies will do better for themselves in the long run than those that take a Realist view. In short, better to 'get with the program' than wait till it gets to you.

Finally, there is an intriguing but more controversial possibility for agency at the macro-level, in the form of the world system being an agent in its own development. I have not argued that here, limiting my treatment of the macro-level process to its non-intentional aspect. Yet, like states today, a completed world state would be an intentional actor. Such an actor could not intend its own creation (that would be backward causation), but it seems counter-intuitive to think that prior to its emergence there would be no intentionality at all at the system level, until it suddenly appears fully formed in a world state. Instead, it seems more plausible to suggest that the process of world state formation involves a progressive 'amplification' of intentionality from individuals and groups to the global level. Early on the degree of systemic intentionality is quite low, but as the system matures it acquires more and more, enabling it increasingly to participate as an agent in its own development. While necessarily imposing boundaries on the agency of its members, it only in this way that they can fully realize their own subjectivity.

\section{Notes}

For too many helpful criticisms and suggestions I am grateful to John Ackerman, Emanuel Adler, Amar Athwal, Michael Barnett, Thomas Biersteker, Deborah Boucoyannis, Mlada Bukovansky, Daniel Drezner, Raymond Duvall, Jörg Friedrichs, Eric Grahn, Xavier Guillaume, Ayten Gundogdu, Dirk Hannemann, Anne Holthoefer, Valerie Hudson, Ian Hurd, Patrick Jackson, Zubin Khambatta, Matthew Kocher, Friedrich Kratochwil, Keith Labedz, Doowan Lee, Thomas Lindemann, Andrew Linklater, Michael Loriaux, Patchen Markell, Jennifer Mitzen, Michelle Murray, David Newstone, Daniel Nexon, Nicholas Onuf, Richard Price, David Sallach, Philippos Savvides, Sebastiao Velasco e Cruz, Lora Viola, David Waldner, Jutta Weldes, George Welton, David Yanowski, Iris Young and three anonymous referees. The article also benefited from reaction to presentations at the University of Chicago, Iowa State University, University of Notre Dame, Ohio State University, University of Toronto, University of Wales at Aberystwyth, University of Wisconsin and the 2002 Annual Meeting of the International Studies Association in New Orleans.

1. For a good overview see especially Kauffmann (1995), and Weber and Depew (1996) on its relationship to neo-Darwinism. By virtue of its interdisciplinary character self-organization thinking has taken a variety of specific forms - the 
theory of autopoiesis, dynamical systems theory, complexity theory, agent-based modeling, and others.

2. See Axelrod (1997), Cederman (1997, 2001), Fearon (1996) and Jervis (1997). It should be noted, however, that the cybernetic and general systems traditions of IR theory in the 1950s and 1960s have important similarities to recent selforganization theory; see Alker (1996: 93, note 28).

3. See Kahler (1999), Thayer (2000) and Thompson (2001); cf. Modelski (1990).

4. For an interdisciplinary sampling, see Luhmann (1995), Epstein and Axtell (1996), Vallacher and Nowak (1997), Witt (1997), Marion (1999) and Macy and Willer (2002).

5. See, for example, Salthe (1993), Christensen (1996), Ulanowicz (1997), Swenson (1997), Marion (1999), Juarrero (1999), Albrecht (2000), McLaughlin (2001) and Weber and Varela (2002).

6. Although their understandings of teleology were notably different, Kant believed that purposiveness was not an objective feature of nature and thus teleological explanations were of heuristic value only, whereas Hegel took the stronger, ontological view that nature itself was teleological. (On this question my approach is Hegelian.) On the differences between their approaches to teleology see deVries (1991) and Dahlstrom (1998), and for discussion of tensions within Kant's position see Kleingeld (1999), Guyer (2000) and Weber and Varela (2002).

7. See Vincent (1983: 202), Nicholson (1990: 225, here referring to the neoHegelian Bernard Bosanquet) and Peperzak (1994).

8. 'Positivist' here includes both empiricist and scientific realist approaches to science, which otherwise differ in various respects (Wendt, 1999: Chapter 2).

9. This assumes that we reject Kant's view that teleological explanations are of heuristic value only.

10. For an exception see Alker (1996: 64-103).

11. My thinking in this section has benefited in particular from discussions with Lora Viola; for her own take on teleological explanation see Viola (2001).

12. This form is also common in functional explanations, and some of today's debate about teleological explanation is motivated by a renewed interest in functionalism, although the two are not identical (see Wright, 1976; McLaughlin, 2001).

13. Machamer (1977) and Cohen (1982: 48; here referring specifically to 'consequence explanations').

14. E.g. von Wright (1971), Hutto (1999), Sehon (2000); in IR see Kratochwil (1989) and Smith (2000).

15. The ultimate issue here - the nature of 'mental causation' - is rooted in the mind-body problem, which has so far defied solution in mechanistic terms (Chalmers, 1996). The case for a teleological reading of intentional explanation turns on that failure.

16. For a defense see Wendt (2004). 
17. These two approaches go back to classic treatments of functionalism by Hempel and Nagel respectively; see McLaughlin (2001).

18. See Asma (1996), Allen et al. (1998) and Short (2002).

19. On Aristotle's conceptualization of final causation see Gotthelf (1987).

20. Both involve material causality, which I shall leave implicit in the following discussion.

21. Examples from IR scholarship include the logic of domino theory and the spiral model (Jervis, 1997: 165-75).

22. On the role of closure in self-organizing systems see Chandler and Van de Vijver (eds) (2000).

23. See Bechtel (1986), Boylan (1986), Salthe (1993) and Sawyer (2001a).

24. For varying treatments of downward causation see Campbell (1974), Juarrero (1999), Emmeche et al. (2000), Meyering (2000), Sawyer (2001b) and Hodgson (2002).

25. Boylan (1986: 22); also see Bechtel (1986: 36), Juarrero (1999: 126) and Hodgson (2001: 359).

26. Pape (1993: 590), Hulswit (1996: 185-6) and Enc and Adams (1998: 388). On multiple realizability see Wendt (1999: 152-6) and the references therein.

27. Words like 'monitor' and 'intervene' might suggest intentionality, but they need not be read that way. The human body, for example, constantly monitors its subsystems and intervenes against pathogens, all without any intentionality.

28. See Mayr (1982), Short (1983: 319), Jackson and Pettit (1993), Hulswit (1996) and Meyering (2000: 189).

29. Whether Waltz's conceptualization of anarchy is up to the task of this argument is another matter; see Wendt (1999).

30. On the general point here see Byerly (1979) and Enc and Adams (1998: 386).

31. As is the case in Kant and Hegel's theories of world system development. Although they do not make the link to teleology, for good discussions of the importance of the interaction between bottom-up and top-down processes in Kant's theory see Huntley (1996) and Harrison (2002); cf. Weber and Varela (2002).

32. For a good summary see Vallacher and Nowak (1997: 82-4); also see Juarrero (1999: 152-5).

33. Hodgson (2001: 350). Various verbs are used in the literature to describe this end-directed effect, such as 'activation', 'entraining', 'harnessing', 'orchestration', and so on; see Byerly (1979: 172), deVries (1991: 62), Enc and Adams (1998: 390-1), Juarrero (1999) and Meyering (2000: 196).

34. This objection provides an occasion to consider the claim that teleological systems 'inevitably' complete their development. Literally this is not true. Organisms may die before they reach maturity, and in international politics one can imagine various exogenous shocks that could prevent world state formation - an asteroid impact, plague, ecological collapse, and so on. All real world systems are partially open systems and thus vulnerable to disruption. On the other hand, a constitutive feature of any teleological system is that it restricts the 
flow of energy across its boundaries, enabling it within limits to determine for itself which stimuli it will respond to (Juarrero, 1999: 143). Sometimes shocks will overwhelm a system and it will collapse, but in their absence a normal teleological system will indeed inevitably finish its development.

35. Juarrero (1999: 143, passim) is quite good on this point.

36. On the ontological status of unobservable entities see Wendt (1999: Chapter 2).

37. Chase-Dunn (1990) also sees Carneiro's estimate as pointing toward a world state.

38. The fact that inter-group struggles within states involve non-state groups is not jeopardized by this assumption, since given the dominance of states at the system level these groups either want states of their own or will eventually resolve their conflicts within state boundaries.

39. See Sugden (1993). Note that the state 'team' might not have a single head, as in a federal or democratic system.

40. For further discussion see Wendt $(1999,2004)$.

41. These parallel the three kinds of contracts that Fichte argued constitute the state as an organism, on which Hegel later drew (Williams, 1997: 296-7).

42. As a concrete reality the Weberian state is a hard case even at the territorial level, where many modern 'states' fail to meet all of its criteria. That is not a problem for the argument here, however, which the latter does not depend on all units in the system being states in the first place, let alone de facto Weberian ones. The failure of some territorial states to satisfy the Weberian ideal simply means that in some areas the process of world state formation has that much farther to go.

43. See especially Varela (1997) and Juarrero (1999) on the simultaneously processual and homeostatic qualities of self-organizing systems.

44. Fukuyama (1992) emphasizes a different material aspect to the struggle for recognition, economics, which is bracketed later.

45. Realists have argued that a world state was necessary for world peace (see Speer, 1968 on Morgenthau), but not that it is inevitable.

46. Deudney (2000: 18-20) also points to E.H. Carr as a forerunner of his argument.

47. The fact that nuclear weapons are possessed by relatively few states limits the force of this argument today, but it will become increasingly powerful if they and other weapons of mass destruction spread.

48. For arguments that Kant's perpetual peace is an unstable equilibrium see Carson (1988) and Guyer (2000: 417).

49. The principal contemporary sources upon which I have drawn are Fukuyama (1992), Honneth (1996), Williams (1997), Pippin (2000) and Baynes (2002).

50. In the latter case difference is a social construction, but may nevertheless present itself as a 'brute fact' to those who are excluded from the group.

51. These correspond roughly to Honneth's (1996) categories of legal and social esteem recognition.

52. For further discussion of this suggestion see Fukuyama (1992). 
53. Williams (1997: 63), Ringmar (2002: 120-1); also see Fukuyama (1992: 193).

54. Williams (1997: 57); Pippin (2000: 163); also see Baynes (2002).

55. To which we might also add a desire for 'ontological' security; see Mitzen (2003).

56. Given that it makes security the highest end, therefore, we might say that Neorealism is a slave morality.

57. See Linklater (1998), Taylor (1998) and Zerilli (1998).

58. This may be seen as a process of 'epigenesis'; see Etzioni (1963).

59. Historically, much of the consolidation of political authority globally took place in this way; see Kaufman (1997).

60. It might be enough, for example, that states be 'decent' in Rawls' (1999) sense.

61. Cederman (2001) highlights the importance of territorial congruity in securing zones of peace.

62. This is an example of group selection at work; see D. Wilson (1997).

63. Kant (1991a; 1991b); see Hurrell (1990: 190-4) for a good discussion of Kant's ambivalence.

64. Distributional conflict constitutes a fourth potential source of instability. For a critique of the politics of recognition from this perspective see Fraser (2000), and Bauman (2001) for one line of response. This issue deserves a much more sustained treatment than I can give it here. Suffice it to say that, while distributional conflict may complicate and delay world state formation, in my view in a globalizing economy it provides no compelling rationale for the permanent retention of territorial sovereignty.

65. Nicholson (1990: 209), here discussing Bosanquet.

66. Tollaksen (1996: 563), partially quoting David Bohm.

\section{References}

Adler, Emanuel and Michael Barnett (eds) (1998) Security Communities. Cambridge: Cambridge University Press.

Albrecht, Glenn (2000) 'Directionality Theory: Neo-Organicism and Dialectical Complexity', Democracy and Nature 6(3): 401-19.

Alker, Hayward (1996) Rediscoveries and Reformulations. Cambridge: Cambridge University Press.

Allen, Colin, Marc Bekoff and George Lauder (eds) (1998) Nature's Purposes. Cambridge, MA: MIT Press.

Asma, Stephen (1996) 'Darwin's Causal Pluralism', Biology and Philosophy 11(1): $1-20$.

Axelrod, Robert (1997) 'Building New Political Actors', in Robert Axelrod, The Complexity of Cooperation, pp. 121-44. Princeton: Princeton University Press.

Bauman, Zygmunt (2001) 'The Great War of Recognition', Theory, Culture and Society 18(2-3): 137-50.

Baynes, Kenneth (2002) 'Freedom and Recognition in Hegel and Habermas', Philosophy and Social Criticism 28(1): 1-17. 
Bechtel, William (1986) 'Teleological Functional Analyses and the Hierarchical Organization of Nature', in Nicholas Rescher (ed.) Current Issues in Teleology, pp. 26-47. Lanham, MD: University Press of America.

Benjamin, Roger and Raymond Duvall (1985) 'The Capitalist State in Context', in Roger Benjamin (ed.) The Democratic State, pp. 19-57. Lawrence: University of Kansas Press.

Blau, Peter (1963) 'Critical Remarks on Weber's Theory of Authority', American Political Science Review 57(2): 305-16.

Boylan, Michael (1986) 'Monadic and Systemic Teleology', in Nicholas Rescher (ed.) Current Issues in Teleology, pp. 15-25. Lanham, MD: University Press of America.

Brewer, Marilynn (1991) 'The Social Self: On Being the Same and Different at the Same Time', Personality and Social Psychology Bulletin 17(5): 475-82.

Bull, Hedley (1977) The Anarchical Society. New York: Columbia University Press.

Burbidge, John (1997) 'The Cunning of Reason', in Richard Hassing (ed.) Final Causality in Nature and Human Affairs, pp. 151-62. Washington, DC: Catholic University of America Press.

Buss, Leo (1987) The Evolution of Individuality. Princeton: Princeton University Press.

Buzan, Barry, Charles Jones and Richard Little (1993) The Logic of Anarchy. New York: Columbia University Press.

Byerly, Henry (1979) 'Teleology and Evolutionary Theory: Mechanisms and Meanings', Nature and System 1: 157-76.

Campbell, David (1992) Writing Security. Minneapolis: University of Minnesota Press.

Campbell, Donald (1974) “"Downward Causation” in Hierarchically Organized Biological Systems', in Francisco Ayala and Theodosius Dobzhansky (eds) Studies in the Philosophy of Biology, pp. 179-86. Berkeley: University of California Press.

Carneiro, Robert (1978) 'Political Expansion as an Expression of the Principle of Competitive Exclusion', in Ronald Cohen and Elman Service (eds) Origins of the State, pp. 205-23. Philadelphia: Institute for the Study of Human Issues.

Carson, Thomas (1988) 'Perpetual Peace: What Kant Should Have Said', Social Theory and Practice 14(2): 173-214.

Cederman, Lars-Erik (1997) Emergent Actors in World Politics. Princeton: Princeton University Press.

Cederman, Lars-Erik (2001) 'Modeling the Democratic Peace as a Kantian Selection Process', Journal of Conflict Resolution 45(4): 470-502.

Chalmers, David (1996) The Conscious Mind. Oxford: Oxford University Press.

Chandler, Jerry and Gertrudis Van de Vijver (eds) (2000) 'Closure: Emergent Organizations and their Dynamics', Annals of the New York Academy of Sciences 901: 1-349.

Chase-Dunn, Christopher (1990) 'World State Formation: Historical Processes and Emergent Necessity', Political Geography Quarterly 9(2): 108-30.

Christensen, Wayne (1996) 'A Complex Systems Theory of Teleology', Biology and Philosophy 11(3): 301-20. 
Cohen, G.A. (1982) 'Functional Explanation, Consequence Explanation, and Marxism', Inquiry 25(1): 27-56.

Cross, Charles (1991) 'Explanation and the Theory of Questions', Erkenntnis 34(2): 237-60.

Cusack, Thomas and Richard Stoll (1994) 'Collective Security and State Survival in the Interstate System', International Studies Quarterly 38(1): 33-59.

Dahl, Robert (1994) 'A Democratic Dilemma: System Effectiveness Versus Citizen Participation', Political Science Quarterly 109(1): 23-34.

Dahlstrom, Daniel (1998) 'Hegel's Appropriation of Kant's Account of Teleology in Nature', in Stephen Houlgate (ed.) Hegel and the Philosophy of Nature, pp. 167-88. Albany: State University of New York Press.

Davidson, Donald (1963) 'Actions, Reasons, and Causes', Journal of Philosophy 60(23): 685-700.

Deudney, Daniel (1995) 'Nuclear Weapons and the Waning of the Real-State', Daedalus 124(2): 209-31.

Deudney, Daniel (1999) 'Geopolitics and Change', in Michael Doyle and G. John Ikenberry (eds) New Thinking in International Relations Theory, pp. 91-123. Boulder, CO: Westview Press.

Deudney, Daniel (2000) 'Regrounding Realism', Security Studies 10(1): 1-45.

DeVries, Willem (1991) 'The Dialectic of Teleology', Philosophical Topics 19(2): 51-70.

Elster, Jon (1982) 'Marxism, Functionalism, and Game Theory', Theory and Society 11(4): 453-82.

Elster, Jon (1995) 'Strategic Uses of Argument', in Kenneth Arrow, Robert H. Mnookin, Lee Ross, Amos Tversky, and Robert Wilson (eds) Barriers to Conflict Resolution, pp. 236-57. New York: W.W. Norton and Company.

Emmeche, Claus, Simo Koppe and Frederik Stjernfelt (2000) 'Levels, Emergence, and Three Versions of Downward Causation', in Peter Bogh Andersen, Claus Emmeche, Niels Ole Finneman and Peder Voetmann Christiansen (eds) Downward Causation, pp. 13-34. Aarhus: Aarhus University Press.

Enc, Berent and Fred Adams (1998) 'Functions and Goal-Directedness', in Colin Allen, Marc Bekoff and George Lauder (eds) Nature's Purposes, pp. 371-94. Cambridge, MA: MIT Press.

Epstein, Joshua and Robert Axtell (1996) Growing Artificial Societies: Social Science from the Bottom Up. Cambridge, MA: MIT Press.

Etzioni, Amitai (1963) 'The Epigenesis of Political Communities at the International Level', American Journal of Sociology 68(4): 407-21.

Fearon, James (1996) 'Causes and Counterfactuals in Social Science: Exploring an Analogy Between Cellular Automata and Historical Processes', in Philip Tetlock and Aaron Belkin (eds) Counterfactual Thought Experiments in World Politics, pp. 39-67. Princeton: Princeton University Press.

Fraser, Nancy (2000) 'Rethinking Recognition', New Left Review 3(May-June): 107-20.

Friedrichs, Jörg (2001) 'The Meaning of New Medievalism', European Journal of International Relations 7(4): 475-502. 
Fukuyama, Francis (1992) The End of History and the Last Man. New York: Avon Books.

Gotthelf, Allan (1987) 'Aristotle's Conception of Final Causality', in Allan Gotthelf and James G. Lennox (eds) Philosophical Issues in Aristotle's Biology, pp. 204-42. Cambridge: Cambridge University Press.

Griffin, David Ray (2003) 'Beyond Anarchy, Plutocracy, and Imperialism: The Need for Global Democracy’ (tentative title). Mimeo, Claremont Graduate School.

Gruber, Lloyd (2000) Ruling the World: Power Politics and the Rise of Supranational Institutions. Princeton: Princeton University Press.

Guyer, Paul (2000) 'Nature, Morality, and the Possibility of Peace', in Paul Guyer, Kant on Freedom, Law, and Happiness, pp. 408-34. Cambridge: Cambridge University Press.

Harrison, Albert (1997) After Contact: The Human Response to Extraterrestrial Life. New York: Plenum Press.

Harrison, Ewan (2002) 'Waltz, Kant and Systemic Approaches to IR', Review of International Studies 28(1): 143-62.

Hegel, G.W.F. (1977) Phenomenology of Spirit. Oxford: Clarendon Press.

Heller, Mark (1982) 'The Use and Abuse of Hobbes: The State of Nature in International Relations', Polity 13(1): 21-32.

Herz, John (1957) 'Rise and Demise of the Territorial State', World Politics 9(4): 473-93.

Hobbes, Thomas (1968) Leviathan. London: Penguin Books.

Hodgson, David (2001) 'Constraint, Empowerment, and Guidance: A Conjectural Classification of Laws of Nature', Philosophy 76(3): 341-70.

Hodgson, Geoffrey (2002) 'Reconstitutive Downward Causation', in Edward Fullbrook (ed.) Intersubjectivity in Economics, pp. 159-80. London: Routledge.

Hollis, Martin and Steve Smith (1990) Explaining and Understanding International Relations. Oxford: Clarendon Press.

Honneth, Axel (1996) The Struggle for Recognition. Cambridge, MA: MIT Press.

Hulswit, Menno (1996) 'Teleology: A Peircean Critique of Ernst Mayr's Theory', Transactions of the Charles S. Peirce Society 32(2): 182-214.

Huntley, Wade (1996) 'Kant's Third Image: Systemic Sources of the Liberal Peace', International Studies Quarterly 40(1): 45-76.

Hurrell, Andrew (1990) 'Kant and the Kantian Paradigm in International Relations', Review of International Studies 16(3): 183-205.

Hutto, Daniel (1999) 'A Cause for Concern: Reasons, Causes and Explanations', Philosophy and Phenomenological Research 59(2): 381-401.

Jackson, Frank and Philip Pettit (1993) 'Structural Explanation in Social Theory', in David Charles and Kathleen Lennon (eds) Reduction, Explanation, and Realism, pp. 97-131. Oxford: Oxford University Press.

Jackson, Patrick and Daniel Nexon (1999) 'Relations Before States', European Journal of International Relations 5(3): 291-332.

Jacobs, Jonathan (1986) 'Teleological Form and Explanation', in Nicholas Rescher (ed.) Current Issues in Teleology, pp. 49-55. Lanham, MD: University Press of America. 
Jervis, Robert (1997) System Effects: Complexity in Political and Social Life. Princeton: Princeton University Press.

Juarrero, Alicia (1999) Dynamics in Action: Intentional Behavior as a Complex System. Cambridge, MA: MIT Press.

Kahler, Miles (1999) 'Evolution, Choice, and International Change', in David Lake and Robert Powell (eds) Strategic Choice and International Relations, pp. 16596. Princeton: Princeton University Press.

Kant, Immanuel (1991a) 'Idea for a Universal History with a Cosmopolitan Purpose', in Hans Reiss (ed.) Kant: Political Writings, pp. 41-53. Cambridge: Cambridge University Press.

Kant, Immanuel (1991b) 'Perpetual Peace: A Philosophical Sketch', in Hans Reiss (ed.) Kant: Political Writings, pp. 93-130. Cambridge: Cambridge University Press.

Kauffman, Stuart (1995) At Home in the Universe. Oxford: Oxford University Press.

Kaufman, Stuart (1997) 'The Fragmentation and Consolidation of International Systems', International Organization 51(2): 173-208.

Kavka, Gregory (1987) 'Nuclear Weapons and World Government', The Monist 70(3): 298-315.

Keohane, Robert (1990) 'International Liberalism Reconsidered', in John Dunn (ed.) The Economic Limits to Modern Politics, pp. 165-94. Cambridge: Cambridge University Press.

King, Gary, Robert Keohane and Sidney Verba (1994) Designing Social Inquiry. Princeton: Princeton University Press.

Kleingeld, Pauline (1999) 'Kant, History, and the Idea of Moral Development', History of Philosophy Quarterly 16(1): 59-80.

Kratochwil, Friedrich (1989) Rules, Norms, and Decisions. Cambridge: Cambridge University Press.

Kymlicka, Will (1995) Multicultural Citizenship. Oxford: Oxford University Press.

Linklater, Andrew (1998) The Transformation of Political Community. Columbia, SC: University of South Carolina Press.

Luhmann, Niklas (1995) Social Systems. Stanford: Stanford University Press.

Machamer, Peter (1977) 'Teleology and Selective Processes', in Robert Colodny (ed.) Logic, Laws, and Life, pp. 129-42. Pittsburgh: University of Pittsburgh Press.

McLaughlin, Peter (2001) What Functions Explain. Cambridge: Cambridge University Press.

Macy, Michael and Robert Willer (2002) 'From Factors to Actors: Computational Sociology and Agent-Based Modeling', Annual Review of Sociology 28: 143-66.

Marion, Russ (1999) The Edge of Organization: Chaos and Complexity Theories of Formal Social Systems. Thousand Oaks: Sage Publications.

Mayr, Ernst (1982) 'Teleological and Teleonomic: A New Analysis', in Henry Plotkin (ed.) Learning, Development, and Culture, pp. 17-38. New York: John Wiley \& Sons. 
Mearsheimer, John (2001) The Tragedy of Great Power Politics. New York: Norton.

Meyering, Theo (2000) 'Physicalism and Downward Causation in Psychology and the Special Sciences', Inquiry 43(2): 181-202.

Mitzen, Jennifer (2001) 'Toward a Visible Hand: The International Public Sphere in Theory and Practice'. PhD dissertation, University of Chicago.

Mitzen, Jennifer (2003) 'Ontological Security in World Politics', mimeo, University of Chicago.

Modelski, George (1990) 'Is World Politics Evolutionary Learning?', International Organization 44(1): 1-24.

Morgenthau, Hans (1946) Scientific Man vs Power Politics. Chicago: University of Chicago Press.

Neumann, Iver and Jennifer Welsh (1991) 'The Other in European Self-Definition: An Addendum to the Literature on International Society', Review of International Studies 17(4): 327-48.

Nicholson, Peter (1990) The Political Philosophy of the British Idealists. Oxford: Oxford University Press.

Nietzsche, Friedrich (1989) On the Genealogy of Morals. New York: Vintage Books.

Ougaard, Morten and Richard Higgott (eds) (2002) Towards a Global Polity. London: Routledge.

Pape, Helmut (1993) 'Final Causality in Peirce's Semiotics and his Classification of the Sciences', Transactions of the Charles S. Peirce Society 29(4): 581-607.

Peled, Alon (2000) 'The New Sciences, Self-Organization and Democracy', Democratization 7(2): 19-35.

Peperzak, Adriaan (1994) 'Hegel Contra Hegel in his Philosophy of Right: The Contradictions of International Politics', Journal of the History of Philosophy 32(2): 241-63.

Pierson, Paul (2000) 'Increasing Returns, Path Dependence, and the Study of Politics', American Political Science Review 94(2): 251-67.

Pippin, Robert (2000) 'What is the Question for which Hegel's Theory of Recognition is the Answer?', European Journal of Philosophy 8(2): 155-72.

Rawls, John (1999) The Law of Peoples. Cambridge: Harvard University Press.

Ringmar, Erik (1996) 'On the Ontological Status of the State', European Journal of International Relations 2(4): 439-66.

Ringmar, Erik (2002) 'The Recognition Game: Soviet Russia against the West', Cooperation and Conflict 37(2): 115-36.

Ruggie, John (1993) 'Territoriality and Beyond: Problematizing Modernity in International Relations', International Organization 47(1): 139-74.

Ruggie, John (1998) 'What Makes the World Hang Together?', International Organization 52(4): 855-85.

Salthe, Stanley (1993) Development and Evolution. Cambridge, MA: MIT Press.

Salthe, Stanley and Koichiro Matsuno (1995) 'Self-Organization in Hierarchical Systems', Journal of Social and Evolutionary Systems 18(4): 327-38. 
Sandel, Michael (1982) Liberalism and the Limits of Justice. Cambridge: Cambridge University Press.

Sawyer, Keith (2001a) 'Emergence in Sociology: Contemporary Philosophy of Mind and Some Implications for Sociological Theory', American Journal of Sociology 107(3): 551-85.

Sawyer, Keith (2001b) 'Simulating Emergence and Downward Causation in Small Groups', in Scott Moss and Paul Davidson (eds) Multi-Agent-Based Simulation, pp. 49-67. Berlin: Springer-Verlag.

Schelling, Thomas (1971) 'Dynamic Models of Segregation', Journal of Mathematical Sociology 1(1): 143-86.

Schmitt, Carl (1985) Political Theology: Four Chapters on the Concept of Sovereignty. Cambridge, MA: MIT Press.

Schroeder, Paul (1993) 'The Transformation of Political Thinking, 1787-1848', in Robert Jervis (ed.) Coping with Complexity in the International System, pp. 47-70. Boulder, CO: Westview.

Sehon, Scott (2000) 'An Argument Against the Causal Theory of Action Explanation', Philosophy and Phenomenological Research 60(1): 67-85.

Shaw, Martin (2000) Theory of the Global State. Cambridge: Cambridge University Press.

Short, T.L. (1983) 'Teleology in Nature', American Philosophical Quarterly 20(4): 311-20.

Short, T.L. (2002) 'Darwin's Concept of Final Cause: Neither New nor Trivial', Biology and Philosophy 17(3): 323-40.

Smith, Steve (2000) 'Wendt's World', Review of International Studies 26(1): 151-63.

Speer, James (1968) 'Hans Morgenthau and the World State', World Politics 20(2): 207-27.

Spruyt, Hendrik (1994) The Sovereign State and its Competitors. Princeton: Princeton University Press.

Sugden, Robert (1993) 'Thinking as a Team: Towards an Explanation for Nonselfish Behavior', Social Philosophy and Policy 10(1): 69-89.

Swenson, Rod (1997) 'Autocatakinetics, Evolution, and the Law of Maximum Entropy Production', in Lee Freese (ed.) Advances in Human Ecology, vol. 6, pp. 1-47. Greenwich, CT: JAI Press.

Tamir, Yael (1993) Liberal Nationalism. Princeton: Princeton University Press.

Tamir, Yael (2000) 'Who's Afraid of a Global State?', in Kjell Goldmann, Ulf Hannerz and Charles Westin (eds) Nationalism and Internationalism in the PostCold War Era, pp. 244-67. London: Routledge.

Taylor, Charles (1998) 'Living with Difference', in Anita Allen and Milton Regan (eds) Debating Democracy's Discontent, pp. 212-26. Oxford: Oxford University Press.

Thompson, William (ed.) (2001) Evolutionary Interpretations of World Politics. London: Routledge.

Tollaksen, Jeff (1996) 'New Insights from Quantum Theory on Time, Conscious- 
ness, and Reality', in Stuart Hameroff, Alfred Kaszniak and Alwyn Scott (eds) Toward a Science of Consciousness, pp. 551-67. Cambridge, MA: MIT Press.

Ulanowicz, Robert (1997) Ecology: The Ascendent Perspective. New York: Columbia University Press.

Ullmann-Margalit, Edna (1978) 'Invisible-Hand Explanations', Synthese 39(2): 263-91.

Vallacher, Robin and Andrzej Nowak (1997) 'The Emergence of Dynamical Social Psychology', Psychological Inquiry 8(2): 73-99.

Varela, Francisco (1997) 'Patterns of Life: Intertwining Identity and Cognition', Brain and Cognition 34(1): 72-87.

Vincent, Andrew (1983) 'The Hegelian State and International Politics', Review of International Politics 9(2): 191-205.

Viola, Lora (2001) 'Re-Introducing Final Causation to Social Science: Neofunctionalist Theory and European Integration', Master's Thesis, University of Chicago.

Von Wright, Georg (1971) Explanation and Understanding. Ithaca: Cornell University Press.

Waever, Ole (1995) 'Securitization and Desecuritization', in Ronnie Lipschutz (ed.) On Security, pp. 46-86. New York: Columbia University Press.

Waltz, Kenneth (1979) Theory of International Politics. Reading, MA: AddisonWesley.

Walzer, Michael (1986) 'The Reform of the International System', in Øyvind Østerud (ed.) Studies of War and Peace, pp. 227-40. Oslo: Norwegian University Press.

Weber, Andreas and Francisco Varela (2002) 'Life after Kant: Natural Purposes and the Autopoietic Foundations of Biological Individuality', Phenomenology and the Cognitive Sciences 1(2): 97-125.

Weber, Bruce and David Depew (1996) 'Natural Selection and Self-Organization', Biology and Philosophy 11(1): 33-65.

Weber, Max (1978) Economy and Society. Berkeley: University of California Press.

Wendt, Alexander (1992) 'Anarchy is What States Make of It', International Organization 46(3): 391-425.

Wendt, Alexander (1998) 'On Constitution and Causation in International Relations', Review of International Studies 24(5): 101-17.

Wendt, Alexander (1999) Social Theory of International Politics. Cambridge: Cambridge University Press.

Wendt, Alexander (2001) 'Driving with the Rearview Mirror: On the Rational Science of Institutional Design', International Organization 55(4): 1019-49.

Wendt, Alexander (2004) 'The State as Person in International Theory', Review of International Studies, 30(2) forthcoming.

Williams, Robert (1997) Hegel's Ethics of Recognition. Berkeley: University of California Press.

Wilson, David Sloan (1997) 'Incorporating Group Selection into the Adaptationist Program: A Case Study Involving Human Decision Making', in Jeffrey A. Simpson and Douglas T. Kendrick (eds) Evolutionary Social Psychology, pp. 345-86. Hillsdale, NJ: Erlbaum. 
Wilson, Robert (1994) 'Causal Depth, Theoretical Appropriateness, and Individualism in Psychology', Philosophy of Science 61(1): 55-75.

Wilson, Robert (2001) 'Group-Level Cognition', Philosophy of Science 68 (Proceedings): S262-S273.

Witt, Ulrich (1997) 'Self-Organization and Economics - What is New?', Structural Change and Economic Dynamics 8(4): 489-507.

Wolf, Klaus-Dieter (1999) 'The New Raison d'Etat as a Problem for Democracy in World Society', European Journal of International Relations 5(3): 333-63.

Wright, Larry (1976) Teleological Explanations. Berkeley: University of California Press.

Zerilli, Linda (1998) 'This Universalism Which is Not One', diacritics 28(1): $3-20$. 